\title{
Transparent Conductive Oxides for Organic Electronics
}

\author{
By \\ Graham Blair Murdoch
}

A thesis submitted in conformity with the requirements for the degree of Master of Applied Science

Graduate Department of Materials Science and Engineering University of Toronto

(C) Copyright by Graham Blair Murdoch (2010) 


\title{
Alternative Transparent Conductors for Organic Electronics
}

\author{
M.A.Sc. Thesis 2010 \\ Graham Blair Murdoch \\ Graduate Department of Material Science and Engineering \\ University of Toronto
}

\begin{abstract}
Organic solar cells and organic light emitting diodes are on the forefront of emerging technologies aimed at harnessing light in ways never thought possible. Largearea installations of OLED solid state lighting (SSL), as well as organic photovoltaics (OPVs), will become possible as the efficiencies of these devices continue to rise. All organic solar cells and OLEDs require the use of transparent conductive electrodes. Indium oxide (ITO) is currently the transparent conductor of choice for these applications, due to its unique combination of transparency, high conductivity, durability, and favourable surface properties.

Indium, however, is a rare and expensive metal; proposed large-area installations of OPV cells and OLEDs will add further strain to global indium supply. Transparent conductive materials that are abundant, inexpensive, and which enable efficient and robust organic devices must therefore be developed. In the present work, suitable ITO anode replacement materials are demonstrated for OLEDS, small-molecule, polymer, and $\mathrm{PbS}$ colloidal quantum dot photovoltaics.
\end{abstract}




\section{Acknowledgements}

Throughout the course of the last two years, Ihave had the privilege of working alongside many exceptionally bright, diligent, and gracious individuals. I consider these people my colleagues and also my friends. Without their help and guidance the present work would certainly not have come to fruition, and I would have been deprived of all that they have taught me during our time together.

First and foremost, I would like to thank and acknowledge Dr. Zhenghong Lu, who was an excellent teacher and mentor. Dr. $\mathrm{Lu}$ tried his utmost to foster an environment of free creative expression while providing direction and knowledge necessary for success, and for these I am truly grateful.

I would also like to acknowledge my labmates, Leo Mordoukhovski, Mark Greiner, Michael Helander, Zhibin Wong, Dong Gao, Fanjie Wei, and Sai Wing Tsang, all truly outstanding individuals who were always there to lend a hand and to offer their insights. 


\section{Table of Contents}

\section{Abstract}

Acknowledgements

Table of Contents

\section{List of Tables and Figures}

Chapter 1. Introduction and Motivation.

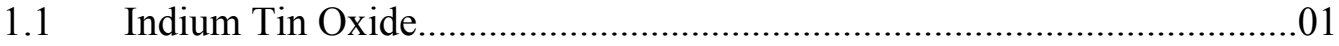

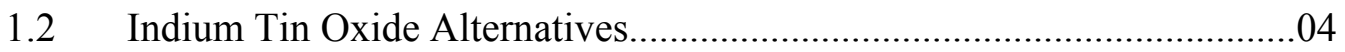

Chapter 2. Overview of organic photovoltaics............................................................09

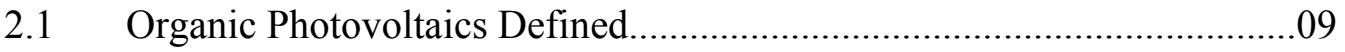

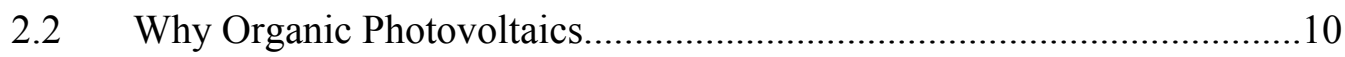

2.2.1 Photovoltaic Technology …....................................................10

2.2.2 The Need for Renewable Energy ..................................................11

2.2.3 Renewable Energy Alternatives - Organic PV and Grid Parity....14

2.3 Device Physics of Organic Solar Cells...................................................18

2.4 Raising Efficiencies and Lowering Costs.............................................22

2.4.1 The 'Exciton Bottleneck' ..............................................................22

2.4.2 Contacts_Efficient ITO Replacement .........................................24

Chapter 3. A Comparison of $\mathrm{CuO}$ and $\mathrm{Cu}_{2} \mathrm{O}$ hole-injection layers for low voltage organic devices.......................................................................................................27

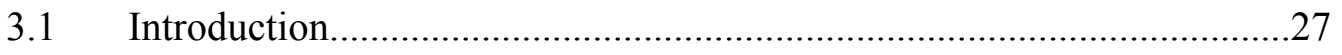

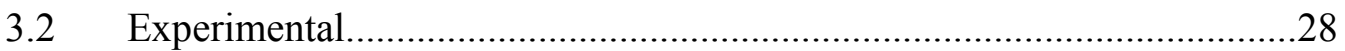

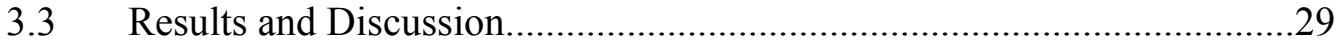

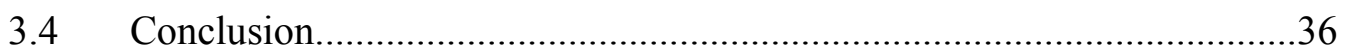

Chapter 4. Aluminum doped zinc oxide for organic photovoltaics...............................37

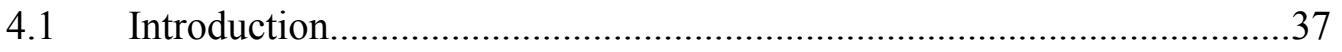

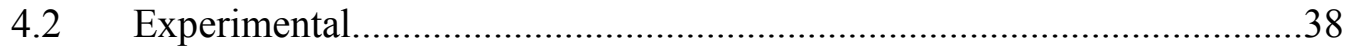




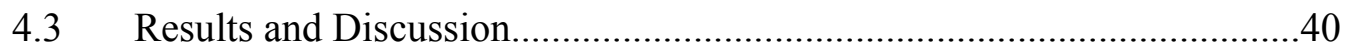

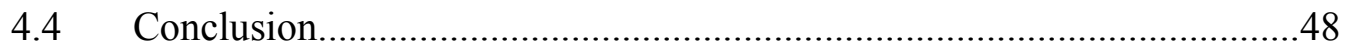

Chapter 5. Transparent Conductive Oxides for Organic Photovoltaics.....................49

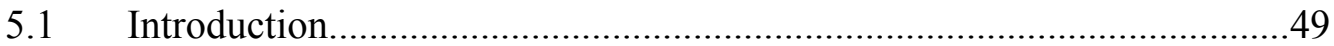

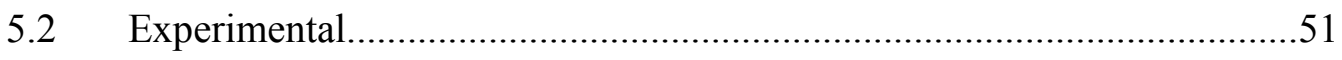

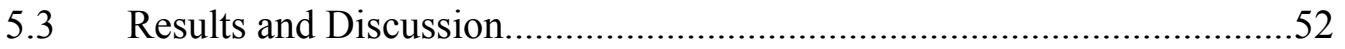

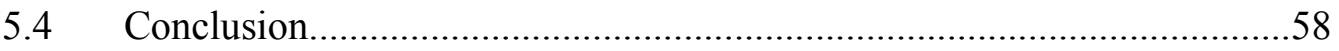

Chapter 6. FTO for PbS Colloidal Quantum Dot Photovoltaics.................................60

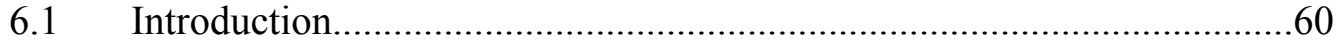

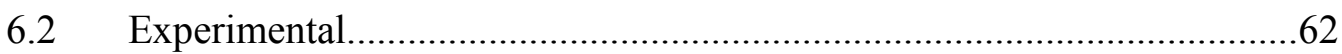

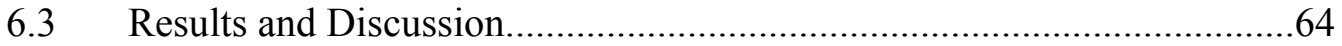

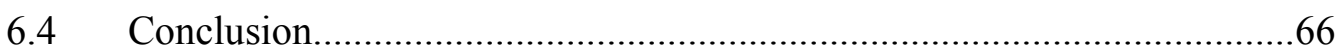

Chapter 7. Summary...............................................................................................................67

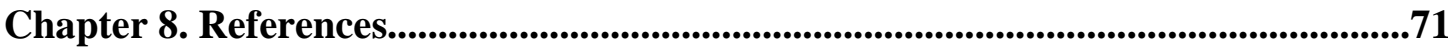




\section{List of Tables and Figures}

Figure 1.1 Band structure of tin doped indium oxide (ITO). Valence and conduction bands arise from $\mathrm{O} 2 \mathrm{p}$ and In $5 \mathrm{~S}$ atomic orbitals. The wide bandgap of indium oxide, combined with degenerate doping of the In $5 \mathrm{~s}$ conduction band provides high transparency and metallic conductivity [2] ................1

Figure 1.2. Unit price of Indium in 1998 dollars per ton from 1987 to 2007 [4]. .........2

Figure 1.3. Worldwide indium production from 2000 to 2008 [4]. ........................... 3

Table 1.1. Carrier concentrations and minimum resistivities achieved for $\mathrm{ZnO}$ doped with various impurity elements. To date, aluminum doped $\mathrm{ZnO}$ (AZO) and gallium doped $\mathrm{ZnO}(\mathrm{GZO})$ have exhibited the highest conductivities of

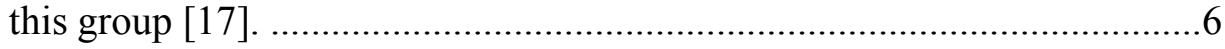

Table 1.2. Summary of binary, ternary, and multicomponent transparent oxide systems showing metallic conductivity. .7

Figure 2.1 Device structure of a typical organic photovoltaic cell, comprising an organic stack, a metallic cathode, and a transparent conductive anode. ....9

Table 2.1. Classification of Photovoltaic Technologies. .........................10

Figure 2.2. Percentage composition of Canada's energy generation capacity as of (2006) [6] ................................................... 12

Table 2.2. Global renewable energy generation capacity by type. $\ldots \ldots \ldots \ldots \ldots \ldots \ldots 15$

Figure 2.3. U.S. landmass required to provide $3.3 \mathrm{TW}$ of solar electricity assuming $200 \mathrm{~W} / \mathrm{m}^{2}$ average insolation and $10 \%$ cell efficiency [8] ...............16

Figure 2.4. Historical photovoltaic price and generation capacity extrapolated to 2023

[9].

Figure 2.5. Continued gains in power conversion efficiency for small molecule and polymer solar cells from 1975 to the present day. Maximum achieved efficiencies for amorphous silicon devices are shown for reference. ......18

Figure 2.6. Depiction of electron-hole pair generation on copper phthalocyanine, a planar organic dye molecule used in organic solar cells.

Figure 2.7. Energy level positions of free and bound electron-hole pairs in organic molecules. The electrostatic force binds electrons and holes together into an exciton, lowering the energy of the electron-hole pair. 
Figure 2.8. Stepwise operation of donor acceptor organic photovoltaic devices: a) absorption, b) relaxation (exciton formation), c) exciton diffusion to donor acceptor interface, d) charge transfer and free carrier generation, e) charge

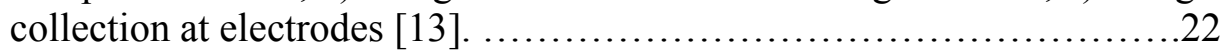

Figure 2.9. Tandem small molecule organic solar cell. Two subcells provide two donor acceptor interfaces for improved light harvesting. The resultant open circuit voltage is the summation of the open circuit voltages of the subcells [15].

Figure 2.10. Equivalent circuit representation of an organic photovoltaic device. For efficient device operation, a small equivalent series resistance and a large equivalent shunt resistance is desirable.

Figure 2.11. $J-V$ characteristics for copper phthalocyanine based organic solar cells fabricated on GZO and ITO anodes. Cells fabricated on GZO show increase series cell resistance due to the existence of an energetic barrier to hole extraction [18]. ............................................25

Figure 3.1. Current density vs. voltage and luminance vs. voltage for OLEDs made with UV-oxidized $\mathrm{Cu}$ and ITO anodes.

Figure 3.2. a) $\mathrm{Cu} 2 \mathrm{p}_{3 / 2} \mathrm{XPS}$ and b) $\mathrm{CuLMM}$ Auger spectra $(h v=1486.6 \mathrm{eV})$ for $5 \mathrm{~nm}$ $\mathrm{Cu}$ films heated at $100^{\circ} \mathrm{C}$ for 60 minutes and UV-ozone treated for 60 minutes.

Figure 3.3. a) Current density vs. voltage for hole-only structures as follows: Anode/NPB $(500 \mathrm{~nm}) / \mathrm{Cu}$. The anodes used were $\mathrm{Cu} / \mathrm{CuO}$ and $\mathrm{Cu} / \mathrm{Cu}_{2} \mathrm{O}$. Fits to the Scott and Malliaras injection model are included as solid lines, along with $\phi_{b}$ values, see Ref. 10 and 11. b) Current density vs. voltage and luminance vs. voltage (inset) for OLEDs made with $\mathrm{CuO}$ and $\mathrm{Cu}_{2} \mathrm{O}$ capped ITO anodes.

Figure 3.4. He I UPS valence band spectra for a) $\mathrm{CuO}$ and b) $\mathrm{Cu}_{2} \mathrm{O}$ substrates with sequential NPB deposition up to a thickness of $12.8 \mathrm{~nm}$. Work function shifts and $\mathrm{C} 1 \mathrm{~s}$ core level shifts vs. NPB thickness are plotted for c) $\mathrm{CuO}$ substrate and d) $\mathrm{Cu}_{2} \mathrm{O}$ substrate.

Figure 4.1. a) Optical Transmission vs. Wavelenth for untreated, DC sputtered AZO films deposited at 8, 12, 16 and $19 \mathrm{~cm}$ target-to-substrate distances. b) Film resistivity for as-deposited and ozone treated AZO vs. target-tosubstrate distance.

Figure 4.2. SEM micrographs of AZO films grown at target-to-substrate distances of a) $19 \mathrm{~cm}$, b) $16 \mathrm{~cm}, \mathrm{c}) 8 \mathrm{~cm}$. .43 
Figure 4.3. a) Current density and b) Photocurrent density vs. voltage for OPV devices made using as-deposited and ozone treated AZO. Current densities were measured under $100 \mathrm{~mW} / \mathrm{cm}^{2}$ and dark conditions. Photocurrent density at a specified voltage was calculated as the difference between device current densities measured under illuminated and dark conditions.

Figure. 4.4. Current density at $100 \mathrm{~mW} / \mathrm{cm}^{2}$ and dark illumination levels vs. voltage for OPV cells made using ozone treated AZO as well as ITO.

Table 4.1. Open circuit voltage $V_{\mathrm{OC}}$, short circuit current density $J_{\mathrm{SC}}$, fill factor $\mathrm{FF}$, Power Conversion Efficiency $\eta_{\mathrm{P}}$, and the calculated series resistance $R_{\mathrm{S}}$ of all cells.

Figure 5.1. Secondary cutoffs (a) and core level shifts (b) for ozone treated and untreated AZO and FTO.

Table 5.1. Open circuit voltage $\mathrm{V}_{\mathrm{OC}}$, short circuit current density $\mathrm{J}_{\mathrm{SC}}$, fill factor FF, Power Conversion Efficiency $\eta_{\mathrm{P}}$, calculated series resistance $\mathrm{R}_{\mathrm{S}}$, and shunt resistance $\mathrm{R}_{\text {shunt }}$ of cells fabricated on various transparent conductive anodes.

Figure 5.2. a) $J V$ curves for PCBM:P3HT solar cells under $100 \mathrm{~mW} / \mathrm{cm}^{2} \mathrm{AM} 1.5 \mathrm{G}$ illumination and dark (inset). b) $J V$ curves for PCBM:P3HT devices fabricated on untreated and ozone treated FTO and AZO under 100 $\mathrm{mW} / \mathrm{cm}^{2} \mathrm{AM} 1.5 \mathrm{G}$ illumination.

Figure 5.3. a) Schematic band alignment of a bulk heterojunction device under the condition $\mathrm{V}_{\mathrm{OC}}<\mathrm{V}_{\mathrm{bi}}$. b) Band alignment of a BHJ device with an electron blocking anode under the condition $\mathrm{V}_{\mathrm{OC}}>\mathrm{V}_{\mathrm{bi}}$.

Figure 6.1. Photovoltaic cells ( $a$ and $b$ ) and hole only devices (c and d) employing FTO and ITO anode materials. Device structures are as follows: a) ITO/PbS/Al, b) FTO/PbS/Al, c) ITO/PbS/Au, d) FTO/PbS/Au.

Figure 6.2. AFM image of a) FTO and b) ITO surfaces. The surface of unpolished FTO is much rougher than that of polished ITO. .64

Figure 6.3. Current at $80 \mathrm{~mW} / \mathrm{cm}^{2}$ and dark illumination levels vs. voltage for CQD cells made using ozone treated ITO (device a) and FTO (device b).

Figure 6.4. Current at $80 \mathrm{~mW} / \mathrm{cm}^{2}$ and dark illumination levels vs. voltage for CQD hole-only devices made using ozone treated ITO (device c) and FTO (device d). 


\section{Chapter 1. Introduction and Motivation}

\subsection{Indium Tin Oxide}

Conventional organic photovoltaics (OPVs) and organic light emitting diodes (OLEDs) are generally fabricated on indium tin oxide (ITO) substrates [1]. Indium tin oxide is a transparent conductive oxide that has recently found widespread use in flat panel displays and televisions. ITO is unique in its combination of optical transparency, metallic conductivity, and high work function, making it an excellent contact to p-like organic molecules. ITO is a degenerately doped n-type semiconducting oxide, with bandgap of approximately $3.75 \mathrm{eV}$ [2]. Figure 1.1 shows the band structure of ITO. The wide bandgap formed between the $\mathrm{O} 2 \mathrm{p}^{6}$ states and In $5 \mathrm{~s}$ states permits high transparency, while the degenerate doping of the In $5 \mathrm{~s}$ band by $\mathrm{Sn}^{3+}$ donor states introduces a high density of free electrons.

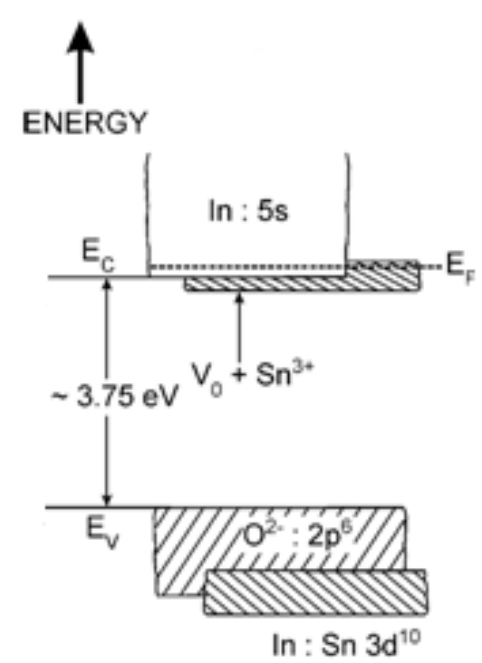

Figure 1.1 Band structure of tin doped indium oxide (ITO). Valence and conduction bands arise from $\mathrm{O} 2 \mathrm{p}$ and $\mathrm{In} 5 \mathrm{~S}$ atomic orbitals. The wide bandgap of indium oxide, 
combined with degenerate doping of the In $5 \mathrm{~s}$ conduction band provides high transparency and metallic conductivity. [2]

The widespread use of ITO in optoelectronic devices has recently become problematic. Surging market demand for indium base metal for use in flat panel displays, combined with limited global reserves of recoverable indium, has led to significant price increases in recent years. The cost of indium tin oxide in 2006 reached more than ten times its price in 2003 [3]. Figure 1.2 shows the price of Indium per ton adjusted for inflation to 1998 dollars [4]. The unit price of indium has historically fluctuated with the business cycle, showing highs and lows approximately every 8 years. The most recent high occurred in 2005, with indium reaching prices of $789,518 \mathrm{USD} / \mathrm{t}$. Taking into account historic price variations, the price rise in 2005 was uncharacteristically large, attributable to sudden demand for flat panel display and televisions production.

\section{Indium Price}

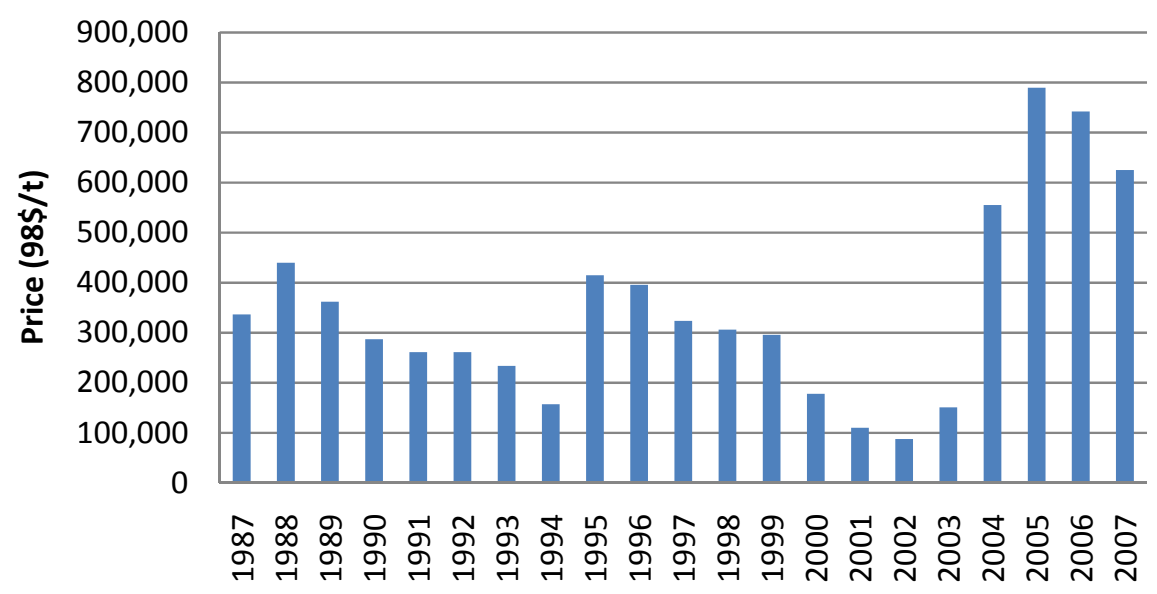

Figure 1.2. Unit price of Indium in 1998 dollars per ton from 1987 to 2007 [4]. 
Since the year 2000, global indium usage has risen exponentially. Indium production currently totals approximately $568 \mathrm{t}$ per year. Refinery production of indium base metal from 2000 onward is given in figure 1.3. [4] USGS data indicate a global economically recoverable indium reserves base of $16,000 \mathrm{t}$ based on concentrations of In in zinc ores [5]. Although estimates have varied due to the inherent difficulty in ascertaining the reserves base [6], an acute pinch in the supply of Indium will almost certainly be felt in the next half century unless suitable alternatives to ITO are adopted; the proposed addition of large-area solar installations, as well the development OLEDbased solid state lighting installations will add entire industrial sectors requiring heavy usage of indium. A one gigawatt copper indium gallium diselenide (CIGS) installation, for instance, requires approximately 50 tons of indium [5]. The demand for indium is therefore expected to grow unabated, necessitating the need for acceptable alternatives to ITO.

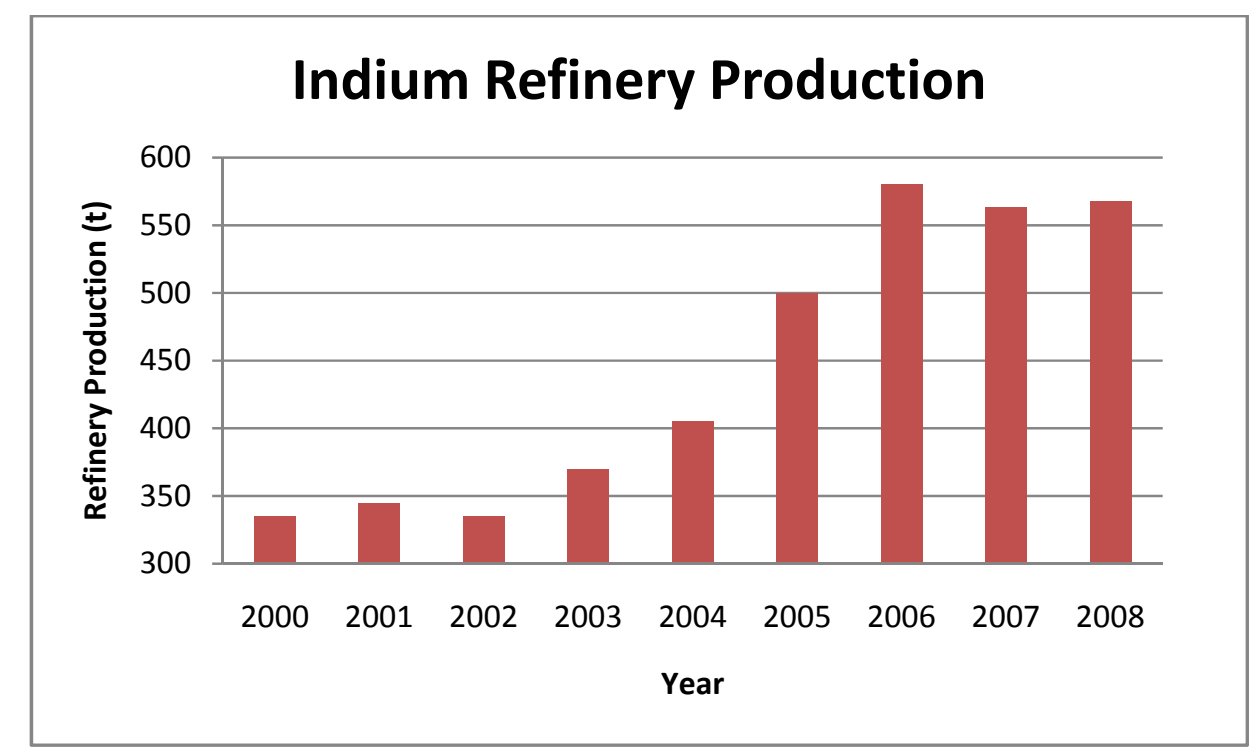

Figure 1.3. Worldwide indium production from 2000 to 2008 [4]. 


\subsection{Indium Tin Oxide Alternatives}

Suitable alternatives to indium tin oxide for use in organic solar and OLED devices must offer the possibility of equivalent or improved device performance as well as cost savings when compared to devices currently made with ITO. Alternatives will have the following characteristics:

- Highly transparent

- Highly conductive

- Suitable surface morphology

- Resistant to chemical attack, thermal, and plasma environments

- Nontoxic

- Durable films

- Low series resistance on contact with organic films

- Material compatibility (wetting, interdiffusion)

- Low cost

- High deposition rate

Over the past 30 years, a number of alternative transparent conductive oxide (TCO) materials have been discovered. Most highly conductive oxides discovered to date have been n-type oxides, although recent work has been done on high-mobility p-type oxides such as $\mathrm{NiO}$ [7], $\mathrm{CuAlO}_{2}$ [8], $\mathrm{CuGaO}_{2}$ [9], $\mathrm{SrCu}_{2} \mathrm{O}_{2}$ [10], and $\mathrm{LaCuOS}$ [11]. The conductivity of these p-type oxides is not currently sufficient to enable their use as ITO replacements. P-type oxides have, however, found widespread use as buffer layers in various organic devices. 
When deposited as ultrathin films $(<10 \mathrm{~nm})$, p-type oxides have been found to improve hole injection into OLED devices, raising device power efficiency by lowering the driving voltage required to inject carriers. Typically, a p-type oxide such as $\mathrm{MoO}_{3}$ [12] or $\mathrm{NiO}$ [13] is deposited as a buffer layer onto an ITO substrate prior to depositing the organic layers. P-type oxide buffer layers have also found use in OPV cells. Recently, a buffer layer of $\mathrm{NiO}$ deposited on an ITO anode was shown to dramatically increase the performance of polymer solar cells. [14] This performance increase was attributed to the ability of the p-type $\mathrm{NiO}$ to extract holes from the polymer layer, while blocking undesired leakage of electrons at the anode contact.

Chapter 3 investigates the use of p-type $\mathrm{Cu}_{2} \mathrm{O} / \mathrm{Cu}$ and $\mathrm{CuO} / \mathrm{Cu}$ bilayers as ITOreplacement anodes for OLED devices. In this work, ultrathin films of copper are surface-oxidized using thermal and ozone means to produce bilayers of conductive copper and copper(I)/copper(II) oxides. Owing to the conductivity of the copper underlayer in both cases, the films could be made to thicknesses of $<15 \mathrm{~nm}$ while still retaining sheet resistances similar to those of ITO films. At these thicknesses, the copper layers were semitransparent, allowing adequate light to escape the OLED devices. With device efficiency comparable to identical devices produced with ITO, the use of oxidized copper layers deposited by simple evaporation offers a low-cost indium-free route for OLED production.

Most commercially used TCOs are n-type thin films of impurity doped binary compounds of $\mathrm{SnO}_{2}$ or $\operatorname{In}_{2} \mathrm{O}_{3}$ deposited by chemical or physical deposition techniques. 
Most recently, zinc oxide has been developed as an alternative TCO material. The discovery of the usefulness of $\mathrm{ZnO}$ as a highly conductive transparent material was made in the early $80 \mathrm{~s}$ [15]. Although undoped films of pure $\mathrm{ZnO}$ are quite conductive $\left(4.5 \times 10^{-4}\right.$ $\Omega \mathrm{cm}$ ), they were found to be thermally unstable beyond $150{ }^{\circ} \mathrm{C}$. Later, the addition of $\mathrm{Al}$ as an impurity was discovered to effectively raise the thermal stability to $400{ }^{\circ} \mathrm{C}$, and lower the resistivity to $1.9 \times 10^{-4} \Omega \mathrm{cm}[16]$. Doping $\mathrm{ZnO}$ with various group III elements such as $\mathrm{Al}, \mathrm{Ga}, \mathrm{In}, \mathrm{B}$ or group IV elements such as $\mathrm{Si}, \mathrm{Ge}, \mathrm{Ti}, \mathrm{Zr}$ and $\mathrm{Hf}$ has since been investigated. Table 1.1 shows the resistivity and carrier densities achieved for $\mathrm{ZnO}$ doped with various impurities [17]. Aluminum and gallium doped zinc oxides have generally shown the lowest resistivities.

Table 1.1. Carrier concentrations and minimum resistivities achieved for $\mathrm{ZnO}$ doped with various impurity elements. To date, aluminum doped $\mathrm{ZnO}$ (AZO) and gallium doped $\mathrm{ZnO}$ (GZO) have exhibited the highest conductivities of this group [17].

\begin{tabular}{llll}
\hline \hline Dopant & $\begin{array}{l}\text { Doping Content } \\
(\text { at.\%) }\end{array}$ & $\begin{array}{l}\text { Resistivity } \\
\left(10^{-4} \Omega \mathrm{cm}\right)\end{array}$ & $\begin{array}{l}\text { Carrier } \\
\text { Concentration } \\
\left(10^{20} \mathrm{~cm}^{-3}\right)\end{array}$ \\
\hline $\mathrm{Al}$ & $1.6-3.2$ & 1.3 & 15.0 \\
$\mathrm{Ga}$ & $1.7-6.1$ & 1.2 & 14.5 \\
$\mathrm{~B}$ & 4.6 & 2.0 & 5.4 \\
$\mathrm{Y}$ & 2.2 & 7.9 & 5.8 \\
$\mathrm{In}$ & 1.2 & 8.1 & 3.9 \\
$\mathrm{Sc}$ & 2.5 & 3.1 & 6.7 \\
$\mathrm{Si}$ & 8.0 & 4.8 & 8.8 \\
$\mathrm{Ge}$ & 1.6 & 7.4 & 8.8 \\
$\mathrm{Ti}$ & 2.0 & 5.6 & 6.2 \\
$\mathrm{Zr}$ & 5.4 & 5.2 & 5.5 \\
$\mathrm{Hf}$ & 4.1 & 5.5 & 3.5 \\
$\mathrm{~F}$ & 0.5 & 4.0 & 5.0 \\
\hline \hline
\end{tabular}


Ternary compounds made from combinations of $\mathrm{SnO}_{2}, \mathrm{In}_{2} \mathrm{O}_{3}, \mathrm{CdO}$ and $\mathrm{ZnO}$ have also been developed in recent years. Typically, these systems exhibit compositiondependant conductivity similar to metallic alloy systems and composition-dependent optical properties similar to mixed films of dielectric materials [17]. Although the use of multicomponent oxides enables rational design of TCO films in terms of their various electrical, optical, chemical and mechanical properties, these films are not widely in use due to the difficulties associated with controlled deposition of multicomponent systems.

Table 1.2. Summary of binary, ternary, and multicomponent transparent oxide systems showing metallic conductivity.

\begin{tabular}{|c|c|}
\hline TCO System & Dopants \\
\hline $\mathrm{SnO}_{2}$ & $\mathrm{Sb}, \mathrm{F}, \mathrm{As}, \mathrm{Nb}, \mathrm{Ta}$ \\
\hline $\mathrm{In}_{2} \mathrm{O}_{3}$ & $\mathrm{Sn}, \mathrm{Ge}, \mathrm{Mo}, \mathrm{F}, \mathrm{Ti}, \mathrm{Zr}, \mathrm{Hf}, \mathrm{Nb}, \mathrm{Ta}, \mathrm{W}, \mathrm{Te}$ \\
\hline $\mathrm{ZnO}$ & $\mathrm{Al}, \mathrm{Ga}, \mathrm{B}, \mathrm{In}, \mathrm{Y}, \mathrm{Sc}, \mathrm{F}, \mathrm{V}, \mathrm{Si}, \mathrm{Ge}, \mathrm{Ti}, \mathrm{Zr}, \mathrm{Hf}$ \\
\hline $\mathrm{CdO}$ & $\mathrm{In}, \mathrm{Sn}$ \\
\hline \multicolumn{2}{|l|}{$\mathrm{ZnO}-\mathrm{SnO}_{2}$} \\
\hline \multicolumn{2}{|l|}{$\mathrm{ZnO}-\mathrm{In}_{2} \mathrm{O}_{3}$} \\
\hline \multicolumn{2}{|l|}{$\mathrm{In}_{2} \mathrm{O}_{3}-\mathrm{SnO}_{2}$} \\
\hline \multicolumn{2}{|l|}{$\mathrm{CdO}-\mathrm{SnO}_{2}$} \\
\hline \multicolumn{2}{|l|}{$\mathrm{CdO}-\mathrm{In}_{2} \mathrm{O}_{3}$} \\
\hline \multicolumn{2}{|l|}{$\mathrm{ZnnO}-\mathrm{In}_{2} \mathrm{O}_{3-} \mathrm{SnO}_{2}$} \\
\hline \multicolumn{2}{|l|}{$\mathrm{CdO}-\mathrm{In}_{2} \mathrm{O}_{3}-\mathrm{SnO}_{2}$} \\
\hline \multicolumn{2}{|l|}{$\mathrm{ZnO}-\mathrm{CdO}-\mathrm{In}_{2} \mathrm{O}_{3}-\mathrm{SnO}_{2}$} \\
\hline \multicolumn{2}{|l|}{$\mathrm{MgIn}_{2} \mathrm{O}_{4}$} \\
\hline $\mathrm{GaInO}_{3}$ & $\mathrm{Sn}, \mathrm{Ge}$ \\
\hline $\mathrm{CdSb}_{2} \mathrm{O}_{6}$ & $\mathrm{Y}$ \\
\hline
\end{tabular}

Despite the fact that TCO materials have been studied for over 40 years, the only materials in practical use are $\mathrm{SnO}_{2}, \mathrm{In}_{2} \mathrm{O}_{3}, \mathrm{ZnO}$, ternary compounds, multicomponent oxides, and doped versions thereof. Table 1.2 summarizes the available transparent oxides exhibiting metallic conductivity. Notably, after one eliminates any oxides containing In and $\mathrm{Cd}$ for the purposes of cost reduction and non-toxicity, one is left with 
impurity doped tin oxides and zinc oxides as remaining practical options. Surprisingly, very little investigation has been carried out on the usage of indium-free TCOs for solar applications. Chapters 4, 5 and 6 are devoted to enabling the usage of indium-free TCOs for small-molecule, polymer, and colloidal quantum dot solar cells. 


\section{Chapter 2: $\quad$ Overview of Organic Photovoltaics}

\subsection{Organic Photovoltaics Defined}

Organic solar cells are photovoltaic cells comprised, in whole or in part, of one or more polymer or small molecule organic compound. Cells typically also comprise other thin film inorganic layers, such as metal or oxide layers or phases. An example of the latter case may include cells having regions in which inorganic nanocystals are embedded into a polymer matrix [1]. Typically, the device structure of an organic photovoltaic cell is a layered stack that includes two electrodes necessary to extract photogenerated charge, and one or more organic layers located between the electrodes. Figure 2.1 depicts this typical structure. As will be discussed, the physics of organic photovoltaic cells differs significantly from traditional crystalline and other thin film PV devices.

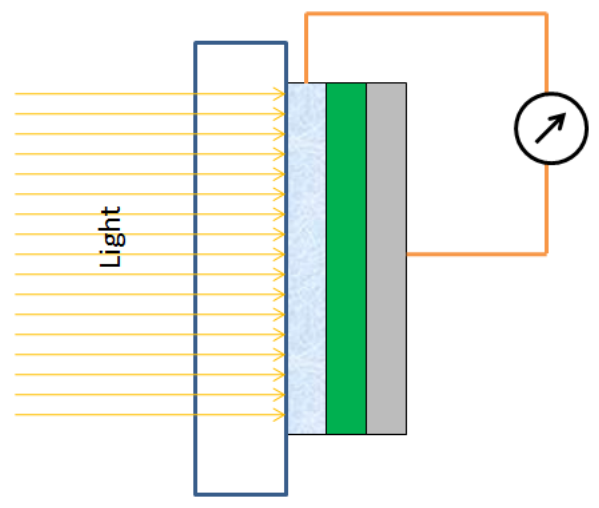

Figure 2.1 Device structure of a typical organic photovoltaic cell, comprising an organic stack, a metallic cathode, and a transparent conductive anode. 


\subsection{Why Organic Photovoltaics?}

\subsubsection{Photovoltaic Technology}

Organic solar cells fall into the general category of 'third-generation' photovoltaic technology. Table 2.1 shows a high level breakdown of the various categories of existing solar technologies.

Table 2.1. Classification of Photovoltaic Technologies

\begin{tabular}{|c|c|c|}
\hline I Generation & II Generation & III Generation \\
\hline $\begin{array}{ll}\text { - } & \text { single crystal wafers } \\
\text { - } & \text { single } p n \text { junction } \\
\text { expensive } & \text { production } \\
\text { max theoretical } \\
\text { efficiency } 31 \%\end{array}$ & $\begin{array}{ll}\text { - } & \text { Thin film deposition } \\
\text { Eg. CIGS, } \alpha-S i, \\
\text { CdTe/CdSe } \\
\text { - } \text { Sputtering, PVD, } \\
\text { CVD, PECVD, } \\
\text { electroplating, etc. } \\
\text { 19.9\% maximum } \\
\text { achieved efficiency } \\
{[4]}\end{array}$ & $\begin{array}{ll}\text { - } & \text { Moderate efficiency/ } \\
\text { ultra low cost } \\
\text { - Ultra high } \\
\text { efficiency/moderate } \\
\text { cost } \\
\text { - Inexpensive } \\
\text { materials } \\
\text { - Low temperature } \\
\text { deposition } \\
\text { High speed roll-to- } \\
\text { roll processing }\end{array}$ \\
\hline
\end{tabular}

First-generation PV devices are based on single-crystalline silicon wafers. In these devices, a single PN junction is used to define the device photoactive region. Given the properties of single-crystalline silicon, and the sun's power spectrum, the maximum theoretical efficiency for this type of device is approximately 30\% (Shockley Quiesser limit) [2]. The highest reported practical efficiency for a single junction silicon cell is $24.7 \%$. [3]

Second generation solar cells are, in general, devices made without the need for single-crystal wafers. Notable examples of this type of technology are CIGS, $\alpha$-Si, and 
$\mathrm{CdTe} / \mathrm{CdSe}$ based cells. Second generation solar cells use well established techniques of thin film processing such chemical vapor deposition (CVD), sputtering, ultrasonic nozzles, electroplating, etc. These types of cells attempt to address the need for large-area solar production while mitigating the high energy and production costs normally associated with first generation devices. The highest reported power conversion efficiency for a second generation device, 19.9\%, was achieved by NREL using a surface-modified CIGS architecture. [4]

Third generation solar cells, to which OPV devices belong, are a further category that offers the promise of greatly reduced cost per watt of generated power. This category encompasses 'future' technology which will greatly enhance efficiency and/or drastically reduce manufacturing costs. Organic solar cells are classified as third generation technology by the latter criterion. Owing to their ability to be easily processed, organic materials are desirable for their inherent potential to reduce overall device costs. The ability of organic materials to be spin coated, spray-coated, and even ink-jet printed on a

roll-to-roll basis can potentially obviate the need for enormously expensive semiconductor fabrication facilities. Furthermore, simple coating processes can eliminate hazardous substances involved in traditional semiconductor and thin film processes.

\subsubsection{The Need for Renewable Energy}

Total global energy consumption is currently estimated to be 15.8 TW [5]. Electrical and mechanical energy production in Canada and the United States is derived predominantly from petroleum, natural gas, coal, nuclear, and hydro, with a very small 
fraction originating from alternative sources. Figure 2.2 shows the percentages of energy generated in Canada for each category [5]. The same approximate energy mix is observed for the United States, with the exception of a greater proportion of hydroelectricity generated in Canada.

\section{Total Energy Consumption in Canada, by Type}

(2006)

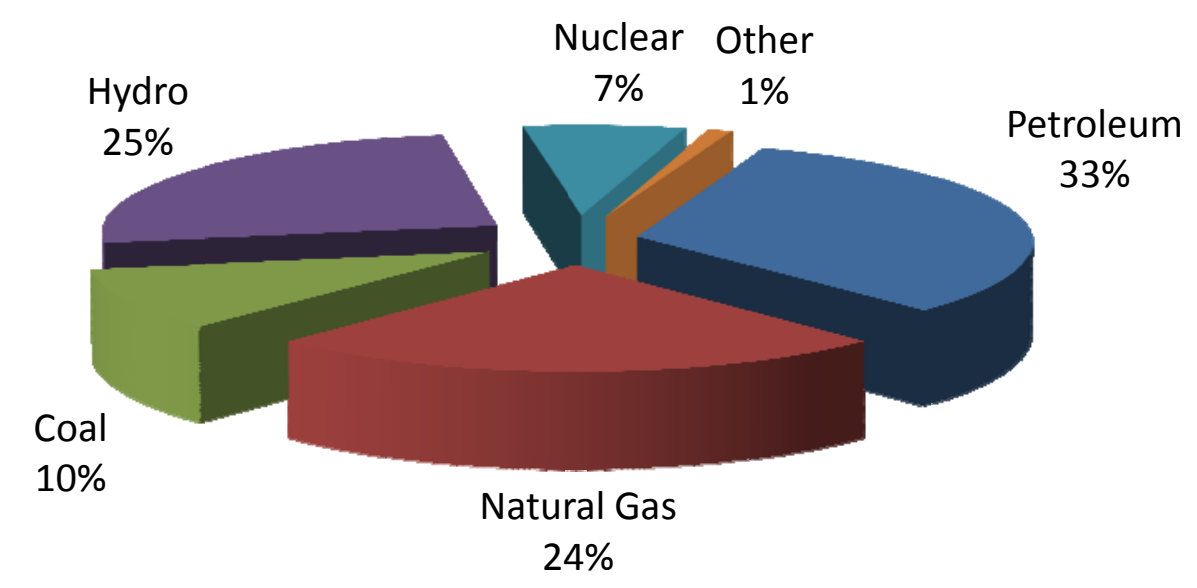

Figure 2.2. Percentage composition of Canada's energy generation capacity as of (2006) [5].

The present global energy mix is dominated by nonrenewable sources. The obvious and controversial question thus arises: for how much longer can the global community stay on its current energy production regimen? Although answers will tend to vary from source to source, it is quite possible to put an rough upper bound on 'how long we have' based on current geological data and extrapolated energy demand. Even according to a conservative estimation, we cannot reasonably hope to sustain our current energy mix beyond two centuries time; at current consumption levels, global reserves of 
coal will be depleted in 137 years, and natural gas in 63 years [6]. As the recovery of dwindling coal, petroleum, and natural gas resources becomes progressively more difficult, energy costs will rise. This is also to say nothing of the environmental toll associated with retaining an energy mix dominated by fossil fuels.

In order for sustainable energy to enter and succeed in the marketplace, it must be as inexpensive and easy to employ as grid power. This concept is called 'grid parity'. Without grid parity, interventions such as legislation to forbid the use of (currently) cheaper non-renewable fossil sources, or the introduction of carbon taxes, are necessary in order to give renewable energy sources an artificial competitive advantage. I remain optimistic, however, that the imposition of legislation and taxes will not be necessary through the efforts of many scientists, engineers and entrepreneurs around the world to create truly competitive sources of energy.

In any foreseeable scenario, the price of energy derived from fossil sources will inexorably rise due to diminishing resources. If cost-competitiveness currently limits the implementation of renewable sources, this barrier will inevitably crumble. The time required, however, to reach this equivalency is the central issue when environmental concerns are factored in. The following questions arise: Will planetary environmental disaster related to the usage of fossil fuels (vis à vis global warming), occur on a time scale faster than the inevitable market changeover to renewable sources, if at all? Secondly: Can government intervention practically accelerate the adoption of a renewable energy mix in the required time frame? If the answer to the first question is no, 
then we need not worry. If the answer to the first question is yes, and the answer to the second question is no, then we have a problem! Assuming, of course, that we are not already past the 'point of no return' in terms of planetary disaster (and I am optimistic that we are not), the best way to proceed is to focus on technology. The development of cheap and sustainable energy - making the answer to the first question a resounding 'yes'-is critical to securing our energy future.

\subsubsection{Renewable Energy Alternatives-Organic PV and Grid Parity}

Discounting solar generation for a moment, the renewable energy options which remain are, in total, insufficient to meet global demand. These options are Hydro, Wind, Biomass, and Geothermal. Hydroelectricity is both an established and competitive generation technology. The problem with hydro, however, exists in the fact that there are simply not enough suitable locations on earth for hydroelectric plants to make a significant contribution to the global energy mix. Similar practical limitations exist for wind, biomass, and geothermal energy sources. Table 2.2 outlines the practical limits for energy generation in each category [7]. We see that the sum total of feasible generation capacities in each category falls below the globally required 16+ TW. Therefore, although the aforesaid options will each occupy a certain definite share in the energy market of the future, we will most certainly require solar energy as a critical component of earth's future energy mix. 
Table 2.2. Global renewable energy generation capacity by type [7].

\begin{tabular}{|c|c|}
\hline Type & Capacity \\
\hline Hydro & $\begin{array}{ll} & \text { - } 1.5 \text { TW Technologically feasible } \\
- & 0.9 \text { TW economically }\end{array}$ \\
\hline Wind & - Practical limit: $2 \mathrm{TW}$ using $4 \%$ of Class $>3$ Land \\
\hline Biomass & $\begin{array}{ll}\text { - } & 0.3 \% \text { efficient } \\
\text { - } & \text { water Limited } \\
\text { - } & 20 \mathrm{TW} \text { would require } 31 \% \text { land use } \\
\text { - } & \text { Practical limit 5-7 TW. } \\
\end{array}$ \\
\hline Geothermal & $\begin{array}{l}\text { - Total continental geothermal potential: } 11.6 \mathrm{TW} \\
\text { - Total oceanic geothermal potential: } 20 \mathrm{TW} \\
\text { - mostly unfeasible: } \\
\text { - cost per meter of drill depth rise } \\
\text { - exponentially } \\
\text { - wells last } 5 \text { years on average before redrilling }\end{array}$ \\
\hline
\end{tabular}

Solar energy has the potential to fill the gap left by other renewable sources. The amount of solar energy flux impinging on the Earth's surface is approximately 10,000 times worldwide energy consumption. As an example, at $10 \%$ solar cell power conversion efficiency and daily average flux of $200 \mathrm{~W} / \mathrm{m}^{2}$ (accounting for night/cloud cover), $1.7 \%$ of the U.S. landmass covered with photovoltaic cells could completely power the most energy hungry nation on earth [7]. Figure 2.3 shows the approximate required area as a fraction of the landmass continental United States. 


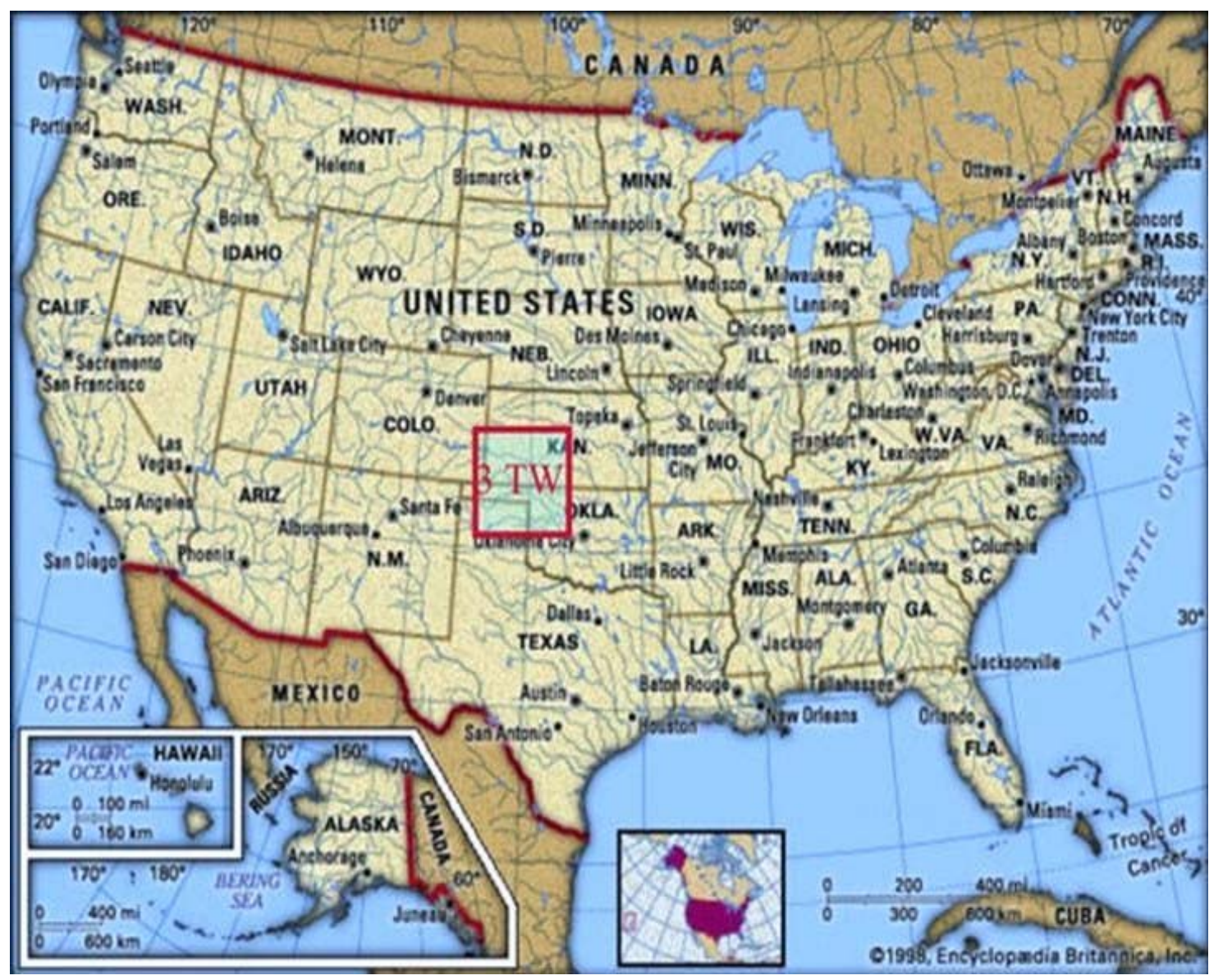

Figure 2.3. U.S. landmass required to provide $3.3 \mathrm{TW}$ of solar electricity assuming $200 \mathrm{~W} / \mathrm{m}^{2}$ average insolation and $10 \%$ cell efficiency. [7]

The relevant parameter determining the economic viability of solar cell technology is the cost per Watt of peak generation capacity, calculated as:

$\$ / W_{P}=\frac{\operatorname{Cost}\left[\$ / \mathrm{m}^{2}\right]}{\text { Peak Efficiency } \times 1000 \mathrm{~W} / \mathrm{m}^{2}}$

Government incentives and carbon taxes notwithstanding, the grid parity cost of energy is approximately $0.3 \$ / \mathrm{W}_{\mathrm{P}}$. Figure 2.4 shows the learning curve for solar cell technology from 1976, extrapolated to 2023 [8]. By 2023, the cost of first-generation crystalline Si devices is expected to level out just above $1 \$ / \mathrm{W}_{\mathrm{P}}$. Similarly, thin film devices are 
expected to level out at approximately $0.5 \$ / \mathrm{W}_{\mathrm{P}}$. New technologies, namely third generation devices including organic solar cells, are expected to take the cost down to grid parity levels, meeting the goal of the U.S. Department of Energy.

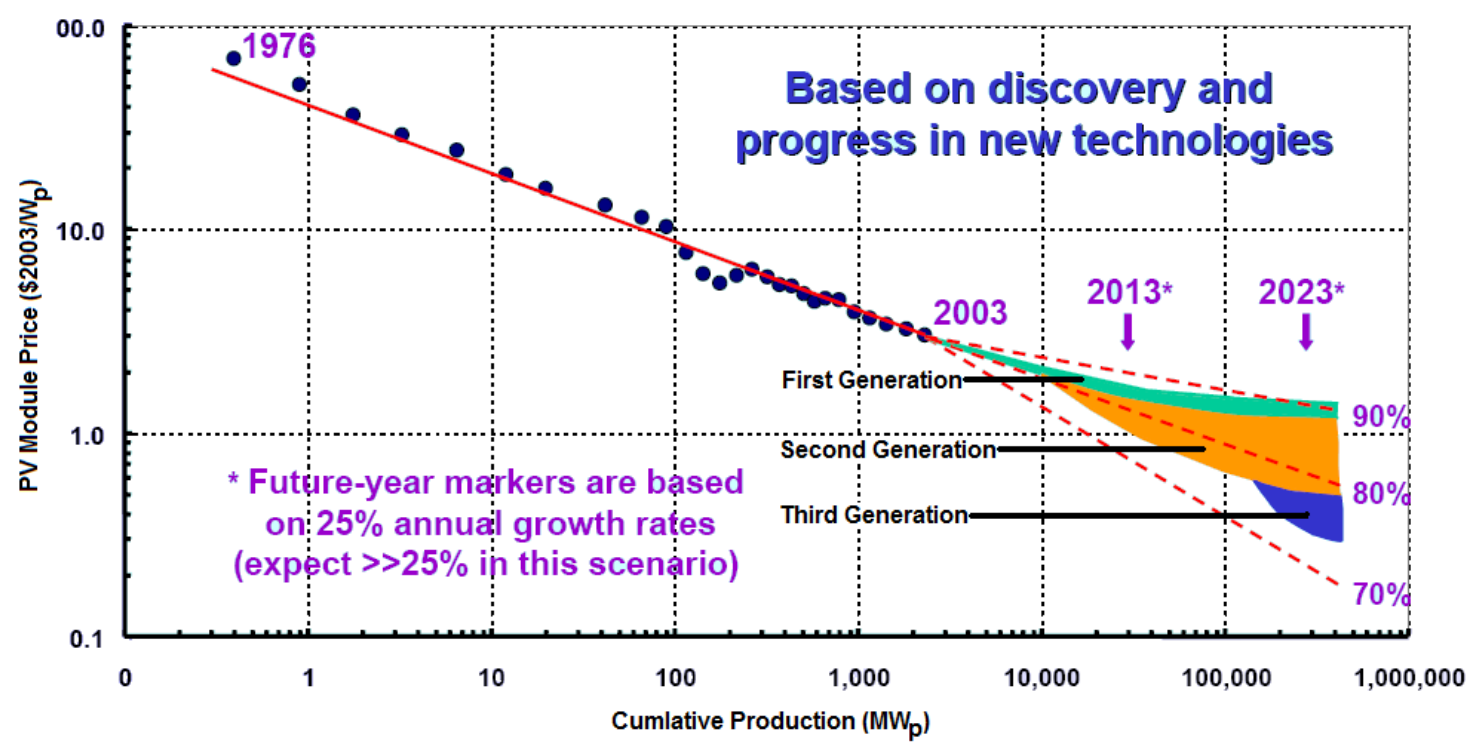

Figure 2.4. Historical photovoltaic price and generation capacity extrapolated to 2023 [8].

The central challenge for organic photovoltaic devices is to raise efficiencies. An approximate upper bound for organic power conversion efficiency was calculated by Stephen R. Forrest to be approximately 20\% [9]. Figure 2.5 tracks the progress of achieved cell efficiencies over three decades. Both polymer- and small molecule-based devices have rivaled each other in efficiency, currently reaching values above $5 \%$. Given the low costs of producing OPV devices, achievement of 15\% PCE will meet and exceed the D.O.E. goal of $0.3 \$ / \mathrm{W}_{\mathrm{P}}$. 


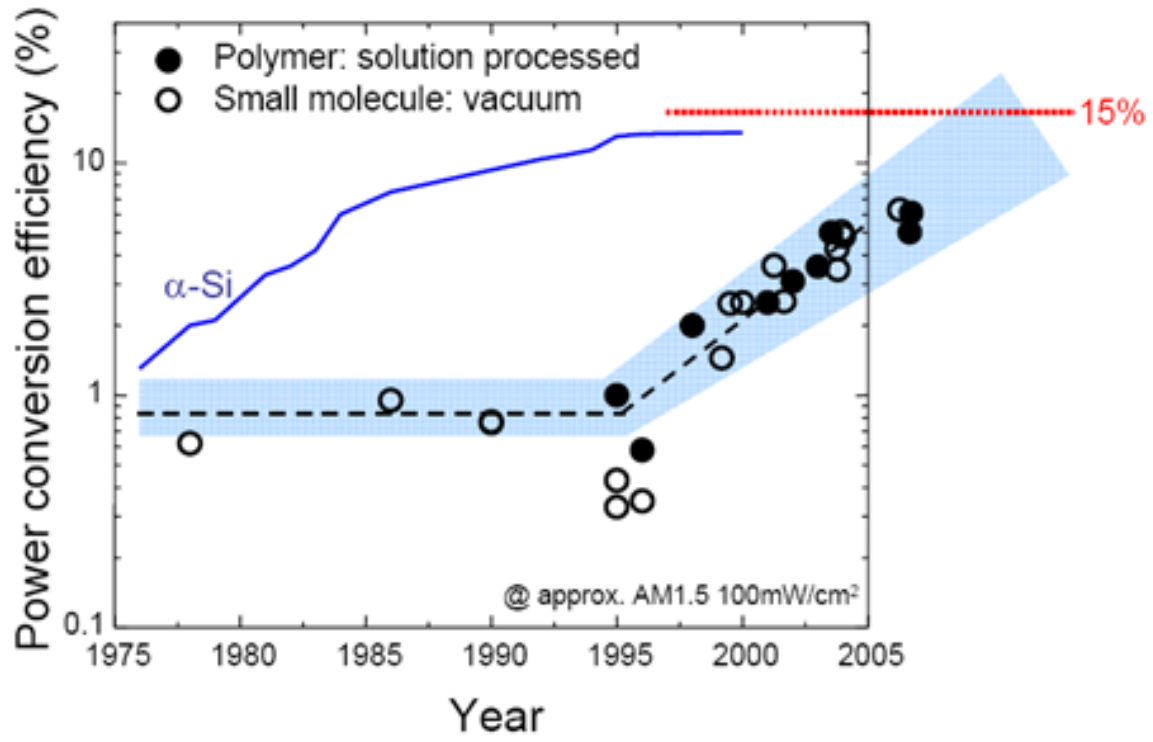

Figure 2.5. Continued gains in power conversion efficiency for small molecule and polymer solar cells from 1975 to the present day. Maximum achieved efficiencies for amorphous silicon devices are shown for reference.

\subsection{Device Physics of Organic Solar Cells}

Organic photovoltaics are unlike traditional single-crystal photovoltaics in a number of respects. In the following section, the basic operation of OPVs will be discussed.

In single-crystalline semiconductor devices, a PN junction is used to create a depletion region with an associated electric field. When photons with energy greater than the bandgap energy of the semiconductor are incident on the PN junction, electron-hole pairs are generated. The built in electric field subsequently sweeps the carriers out of the depletion region, whereupon they exit the crystal to flow through an external load.

An organic solar cell, on the other hand, uses small molecule or polymer substances. Figure 2.6 depicts a small-molecule OPV device comprising a photoactive 
organic layer sandwiched between two electrode contacts. Copper phthalocyanine, a commonly used planar organic absorber material, is shown to illustrate the device. Photons incident on the organic layer cause electron-hole pairs to be generated within individual molecules.
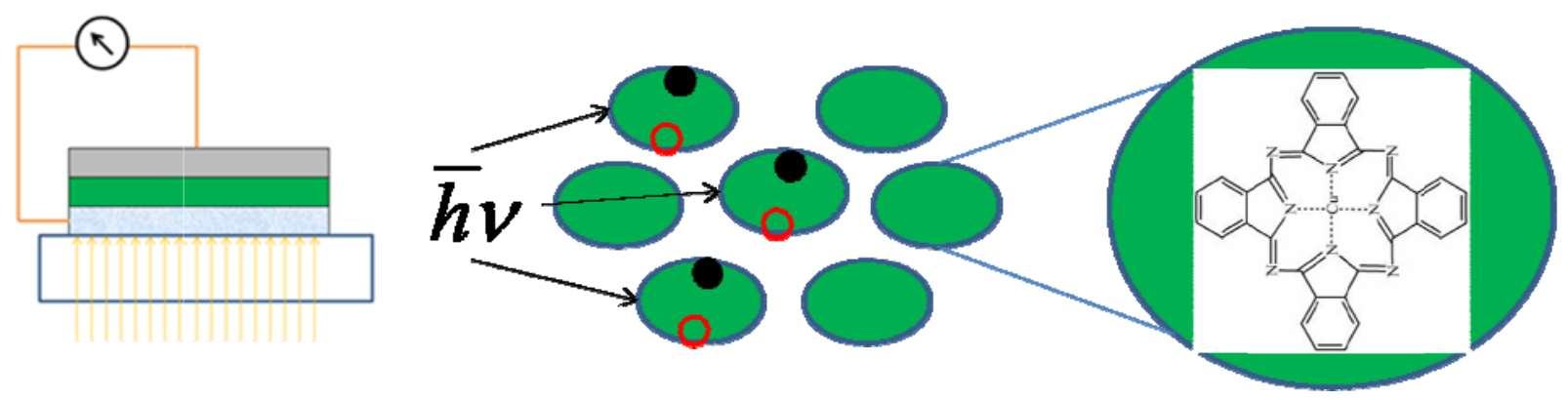

Figure 2.6. Depiction of electron-hole pair generation on copper phthalocyanine, a planar organic dye molecule used in organic solar cells.

For the case of photoactive organic molecules, we cannot use the same band model that was used when considering single crystal cells. Instead of bands, we must consider molecular orbitals arising from bonding and antibonding quantum states. For the case of OPVs, we consider the Highest Occupied Molecular Orbital (HOMO), and Lowest Unoccupied Molecular Orbital (LUMO) analogous to valence and conduction bands in traditional solar cells, respectively. Furthermore, because of the localization of electrons and holes on individual organic molecules, a significant Coulombic force develops between them. This Coulombic force tends to attract the electron and hole together in an orbit. The electrostatically bound electron-hole pair is termed an 'exciton'. The total energy of a bound electron-hole pair tends to be reduced as compared to individually free electrons and holes. This binding energy is given by 
$\frac{e^{2}}{4 \pi \varepsilon_{0} \varepsilon_{r} R_{0}}$

Where $R_{0}$ is the mean radius of the electron-hole pair and $\varepsilon_{r}$ is the relative permittivity of the organic material. The exciton binding energy is typically $0.4 \mathrm{eV}$ to $1.4 \mathrm{eV}$ for most organic materials [10].

In single crystal silicon solar cells, the binding energy of holes and electrons is smaller than $k T$ at room temperature $(0.013 \mathrm{eV})$, due to Silicon's higher dielectric constant. Therefore, excitonic effects in traditional solar devices can generally be ignored. For organic solar cells, however, excitonic effects are pronounced, and pose a definite engineering challenge. Figure 2.7 schematically shows the energy levels of free (left) and bound (right) electron-hole pairs.

\section{Lowest Unoccupied - Molecular Orbital}

\section{Highest Occupied} Molecular Orbital

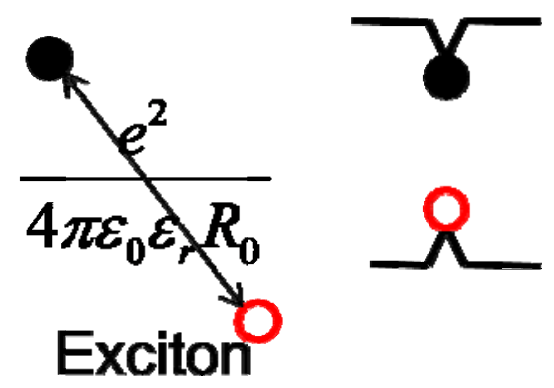

Figure 2.7. Energy level positions of free and bound electron-hole pairs in organic molecules. The electrostatic force binds electrons and holes together into an exciton, lowering the energy of the electron-hole pair.

Before photogenerated electrons and holes can effectively be harvested from an organic layer, they must be separated from each other. The exciton binding energy must be overcome. In order to accomplish this, local electric fields $>5 \times 10^{5} \mathrm{~V} / \mathrm{cm}$ are needed 
[11]. In order to adequately furnish the required electric fields to unbind the electrons and holes, and thus to achieve high device quantum efficiency, donor/acceptor organic systems have been adopted. In these bilayer devices, an electron accepting organic layer with high electron affinity energy is used in tandem with a donor molecule of lower electron affinity. In 1986, tang introduced the first donor acceptor device with power conversion efficiency of a record $1 \%$ [12].

Figure 2.8 depicts the stepwise operation of a typical donor-acceptor device. Incident photons are first absorbed in an ultrafast process, typically requiring only $10^{-15}$ to $10^{-16}$ seconds, producing an electron-hole pair. The optical absorption length of organic absorbers such as the aforementioned copper phthalocyanine is typically $\sim 100 \mathrm{~nm}$. Immediately, the electron and hole relax in energy as they mutually become bound into an exciton. This process requires between $10^{-9}$ to $10^{-13}$ seconds. Having been generated, the excitons in the absorber layer diffuse through the layer. The lifetime for this diffusion before recombination occurs is $\sim 10^{-9}$ seconds. The corresponding diffusion length before recombination is between $5 \mathrm{~nm}$ to $20 \mathrm{~nm}$. Excitons that successfully diffuse to the donoracceptor interface become unbound as the electron is accepted by the organic acceptor material. The charge transfer process is ultrafast, requiring only $\sim 10^{-13}$ seconds. Subsequent to charge separation, free holes and electrons migrate away from the donor acceptor interface and exit through the anode and cathode contacts. [13] 


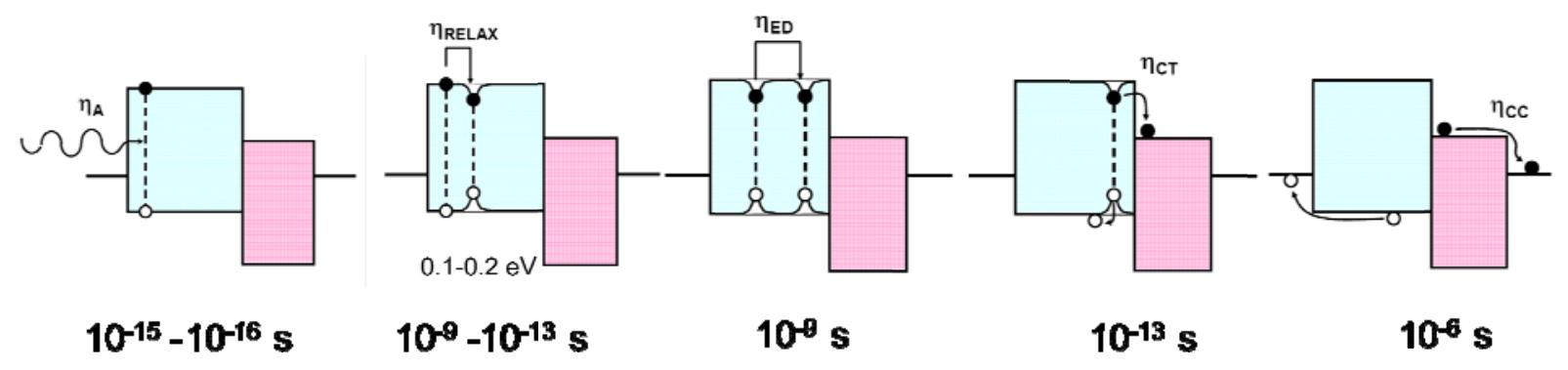

Figure 2.8. Stepwise operation of donor acceptor organic photovoltaic devices: a) absorption, b) relaxation (exciton formation), c) exciton diffusion to donor acceptor interface, d) charge transfer and free carrier generation, e) charge collection at electrodes [13].

\subsection{Raising Efficiencies and Lowering Costs}

\subsubsection{The 'Exciton Bottleneck'}

The central problem of raising the organic photovoltaic device efficiencies arises primarily due to what is termed the 'exciton bottleneck'. It was previously mentioned that the average diffusion lengths of photogenerated excitons in organic materials are between 5 to $20 \mathrm{~nm}$. Furthermore, we know that only excitons that manage to migrate to the donor acceptor interface and dissociate result in useful free electrons and holes. The consequence of these two facts is that only excitons which are formed within $20 \mathrm{~nm}$ of the donor-acceptor interface are useful for energy generation. Unfortunately, the optical absorption length of typical organic materials is $\sim 100 \mathrm{~nm}$. If one is limited to absorption within one diffusion length $(20 \mathrm{~nm})$, it is not possible to capture all of the available light [9]. There have been many attempts to mitigate the exciton bottleneck problem, and significant progress has been made in recent years. One strategy has been to build tandem structures including more than one donor acceptor interface. In this instance, more than 
one photoactive interface is used in series, resulting in a net open circuit voltage that is the summation of the open circuit voltages of the subcells. Figure 2.9 shows the device structure of one such device produced by Forrest et al., yielding a power conversion efficiency of $5.7 \%$. [14]

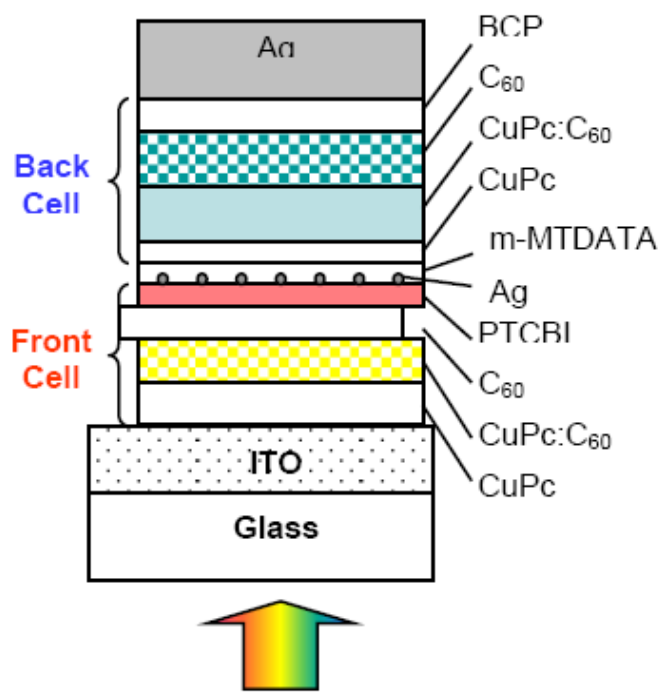

Figure 2.9. Tandem small molecule organic solar cell. Two subcells provide two donor acceptor interfaces for improved light harvesting. The resultant open circuit voltage is the summation of the open circuit voltages of the subcells [14].

Bulk heterojunction devices are also an attempt to raise the effective donor acceptor interface area to capture more of the available light. While this strategy has been effective in raising the active area, one runs into problems of lower carrier mobility as the carriers must wend their way through a film of complex phase structure, occasionally encountering an insurmountable cul-de-sac. Further strategies to overcome the exciton bottleneck include nanostructured interfaces to increase the donor-acceptor interface area 
[15], or the inclusion of metallic nanoparticles to concentrate the optical field at the donor acceptor interface [16].

\subsubsection{Contacts-Efficient ITO Replacement Materials}

Before photogenerated carriers can be used to do work in an external circuit, holes and electrons must exit the organic layers at the anode and cathode, respectively. Charge collection efficiency typically approaches $100 \%$ for this process. This does not mean, however, that barriers at the contacts are unproblematic. If a barrier to hole or electron extraction exists at either the anode or cathode, carriers will tend to lose energy at the organic/electrode interfaces, reducing the open circuit voltage of the cell. Poor contacts result in high cell series resistances. Figure 2.10 shows an equivalent circuit for a typical organic photovoltaic device. For efficient device performance, it is desirable that the series resistance, $R_{S}$, should approach zero, and that the shunt resistance, $R_{\text {Shunt }}$, should approach infinity.

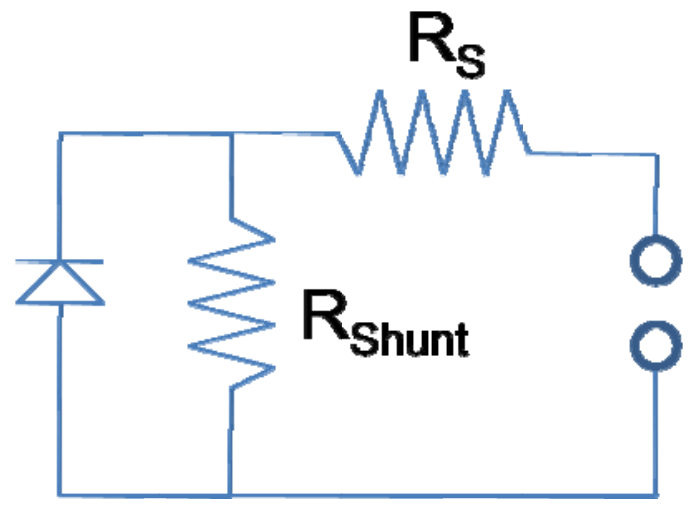

Figure 2.10. Equivalent circuit representation of an organic photovoltaic device. For efficient device operation, a small equivalent series resistance and a large equivalent shunt resistance is desirable. 
Figure 2.11 shows the results of a recent attempt to replace ITO for Gallium doped $\mathrm{ZnO}(\mathrm{GZO})$ as the transparent anode material in a $\mathrm{CuPc} / \mathrm{C} 60$ device [17]. When compared to the device fabricated on ITO, the GZO device exhibited a much larger series resistance. Large series resistance manifests in a reduced slope at the open circuit (zero current) condition. Despite the increased series resistance for the GZO device, the short circuit currents for both devices remained comparable, indicating an equivalent number of carriers exiting the organic system at the contacts. The above attempt to replace ITO with GZO was unsuccessful due to the contact resistance at the GZO anode, lowering device power conversion efficiency.

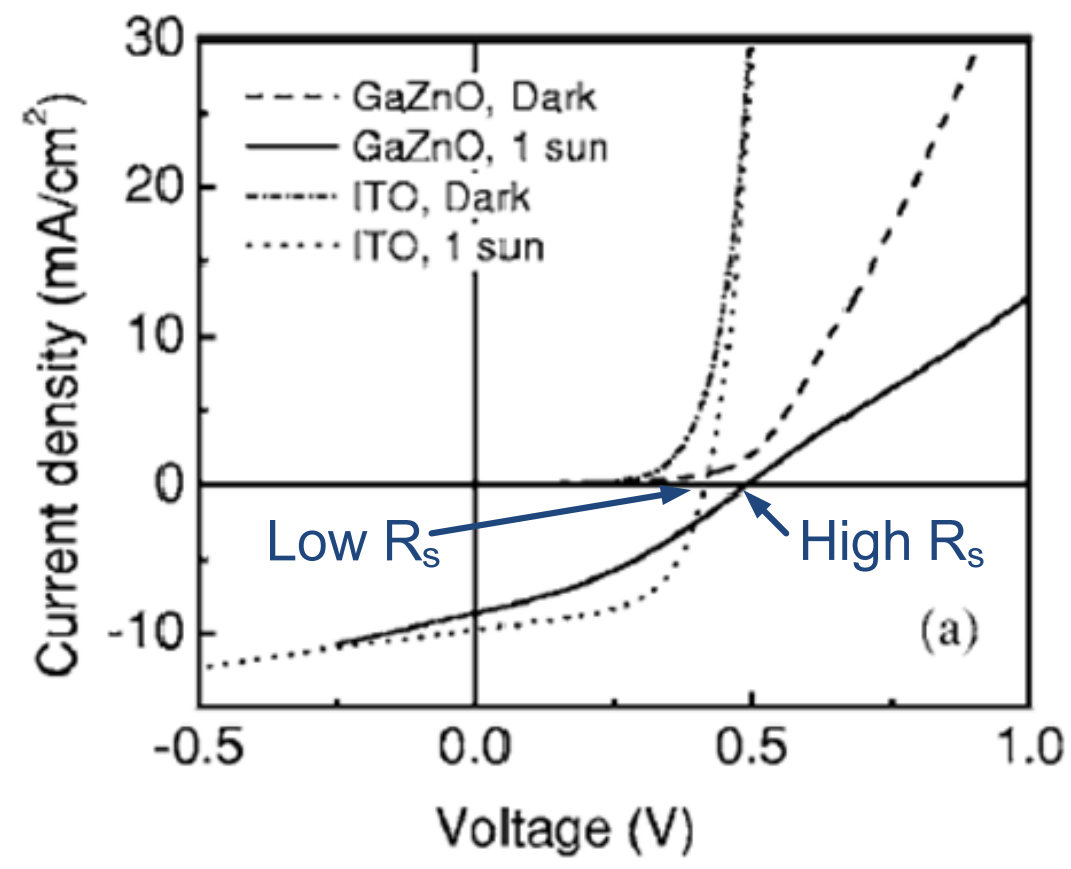

Figure 2.11. $J-V$ characteristics for copper phthalocyanine based organic solar cells fabricated on GZO and ITO anodes. Cells fabricated on GZO show increase series cell resistance due to the existence of an energetic barrier to hole extraction [17]. 
In addition to lowering the series resistance at the electrode contacts, it is desirable to raise device shunt resistance. Low shunt resistances arise when holes and electrons are offered an alternative path to recombine without first traversing the external circuit. If holes and electrons both tend to exit the anode or cathode at the same time, they will recombine, reducing the photocurrent. In this case, one will observe reduced short circuit current, and a smaller shunt resistance, indicated by a larger slope at the short circuit (zero bias) condition. Holes and electrons are produced together in the organic layers when excitons are unbound at donor acceptor interfaces. In bilayer donor acceptor devices, such as the $\mathrm{CuPc} / \mathrm{C} 60$ device shown above, free holes tend to be localized on the donor side of the device, and free electrons tend to be localized on the acceptor side of the device. Because of this geometry, the ability of the electrodes to exclusively extract only holes or electrons is of less consequence to the device shunt resistance. For bulk heterojunction devices, however, holes and electrons occupy the same geometrical volume because donor and acceptor materials are blended together. It is therefore important that an anode contact to such a blend be capable of accepting holes and rejecting electrons, and vice versa for the cathode contact.

The work which follows in chapters 4 and 5 center on finding alternative transparent anode contacts that produce equivalent, or improved device performance for both planar and bulk heterojunction devices. 


\section{Chapter 3. A Comparison of $\mathrm{CuO}$ and $\mathrm{Cu} 2 \mathrm{O}$ hole- injection layers for low voltage organic devices}

\subsection{Introduction}

$\mathrm{Cu}_{2} \mathrm{O}$ and $\mathrm{CuO}$ have been grown with an aim to reduce junction electrical resistance when interfaced with N,N'-bis (1-naphthyl)-N,N'-diphenyl-1,1' biphenyl 4,4'diamine (NPB). Organic light-emitting diodes (OLEDs) employing $\mathrm{Cu} / \mathrm{CuO}$ anodes have equivalent driving-voltages as devices made with indium-tin-oxide (ITO). Hole-injection barriers are calculated from current-voltage characteristics of $\mathrm{CuO} / \mathrm{NPB} / \mathrm{Cu}$ and $\mathrm{Cu}_{2} \mathrm{O} / \mathrm{NPB} / \mathrm{Cu}$ devices via theoretical simulation. Photoelectron spectroscopies are used to measure oxide valence band spectra, interfacial dipole formation, and band bending during in situ sequential deposition of NPB on each oxide. Calculated hole-injection barriers and those derived from photoemission results accord well, explaining superior hole-injection at the $\mathrm{CuO}-\mathrm{NPB}$ interface.

With steady adoption for niche markets such as flat-panel displays, organic electronics are now actively researched for other applications such as organic solid-state lighting, thin film transistors, memory units, photovoltaics, etc. Indium tin oxide (ITO) has been used ubiquitously as an anode material, despite its ever-rising cost and technical challenges in current-driven devices such as organic light-emitting diodes (OLEDs). Recently, the use of metal oxides as hole-injection layers (HILs) for anodes has attracted considerable interest ${ }^{1,2,3,4}$. In particular, the $\mathrm{Cu} / \mathrm{Cu}_{\mathrm{x}} \mathrm{O}$ system has shown promise as an efficient anode contact for OLEDs, ${ }^{5,6}$ organic thin film transistors (OTFTs) ${ }^{7}$ and photovoltaics $^{8}$. In this work, we report that OLEDs based on N,N'-bis (1-naphthyl)N,N'-diphenyl-1,1' biphenyl 4,4'-diamine (NPB) employing ultraviolet (UV) -ozone 
produced $\mathrm{CuO}$, as opposed to $\mathrm{Cu}_{2} \mathrm{O}$ as $\mathrm{HIL}$ exhibits significantly better device performance with particularly low-driving voltage. Using ultraviolet photoelectron spectroscopy (UPS), x-ray photoelectron spectroscopy (XPS), and in situ deposition of NPB we obtain oxide band structure and interface dipole energy for both oxides. Holeinjection barriers into NPB derived from UPS results agree well with transport modelling of single carrier devices, explaining device performance differences in terms of the holeinjection ability of each material.

\subsection{Experimental}

OLED devices were fabricated on glass substrates cleaned in acetone, methanol and deionized water, followed by 15 minute UV-ozone treatment. Reference devices were fabricated on ITO coated glass $(\sim 15 \Omega / \square)$ cleaned in the same manner. Hole-only devices were fabricated on $\mathrm{Si}(100)$ with $2000 \mathrm{~nm}$ furnace oxides for electrical isolation. Metal and organic films were thermally evaporated in separate chambers with base pressures of $\sim 10^{-7}$ Torr and $\sim 10^{-8}$ Torr, respectively. Film thicknesses were monitored using calibrated quartz crystal monitors. As will be shown, $\mathrm{CuO}$ and $\mathrm{Cu}_{2} \mathrm{O}$ oxide layers were produced by ex situ oxidation of freshly deposited $\mathrm{Cu}$ films for 60 minutes by UVozone treatment and annealing in air at $100{ }^{\circ} \mathrm{C}$, respectively.

Immediately after oxidation, organic and cathode layers were deposited to obtain the following OLED structure: Anode/NPB(60 $\mathrm{nm}) /$ tris-(8-hydroxyquinoline) aluminum $\left(\mathrm{Alq}_{3}\right)(45 \mathrm{~nm}) / \mathrm{LiF}(1.5 \mathrm{~nm}) / \mathrm{Al}(100 \mathrm{~nm})$. The structure of the hole-only devices was as follows: Anode / $\operatorname{NPB}(500 \mathrm{~nm}) / \mathrm{Cu}(20 \mathrm{~nm})$. The active area for all devices was $1 \mathrm{~mm} \times 2 \mathrm{~mm}$. Luminance and current density (L-J-V) characteristics were 
measured in ambient atmosphere using an HP4140B pA meter and a Minolta LS-110 Luminance meter. The perpendicular anode and cathode lines were contacted approximately $2 \mathrm{~cm}$ away from device active area. XPS and UPS measurements were performed using a PHI 5500 system with monochromated $\mathrm{Al} \mathrm{K}_{\alpha}$ X-rays $(1486.6 \mathrm{eV})$ and He I UV (21.2 eV). All spectra were calibrated by referencing to the Fermi edge of sputtered Au.

\subsection{Results and Discussion}

Figure 1 compares current density and luminance for OLEDs made with semitransparent $\mathrm{Cu} / \mathrm{CuO}$ and ITO anodes. $\mathrm{Cu}$ film thickness prior to oxidation was optimized at $20 \mathrm{~nm}$, compromising between optical transparency and series sheet resistance. The $\mathrm{Cu} / \mathrm{CuO}$ anode device exhibited approximately equal driving voltage as the ITO baseline device, despite lower transparency and larger sheet resistance of the $\mathrm{Cu} / \mathrm{CuO}$ anode (25 $\Omega / \square$ as opposed to $15 \Omega / \square$ for ITO). The driving voltage at 8000 $\mathrm{cd} / \mathrm{m}^{2}$ luminance was $7.4 \mathrm{~V}$ for the $\mathrm{Cu} / \mathrm{CuO}$ device compared with $7.6 \mathrm{~V}$ for the ITO reference device. Past $7 \mathrm{~V}$, the $\mathrm{Cu} / \mathrm{CuO}$ device overtakes the ITO device in both current density and luminance. 


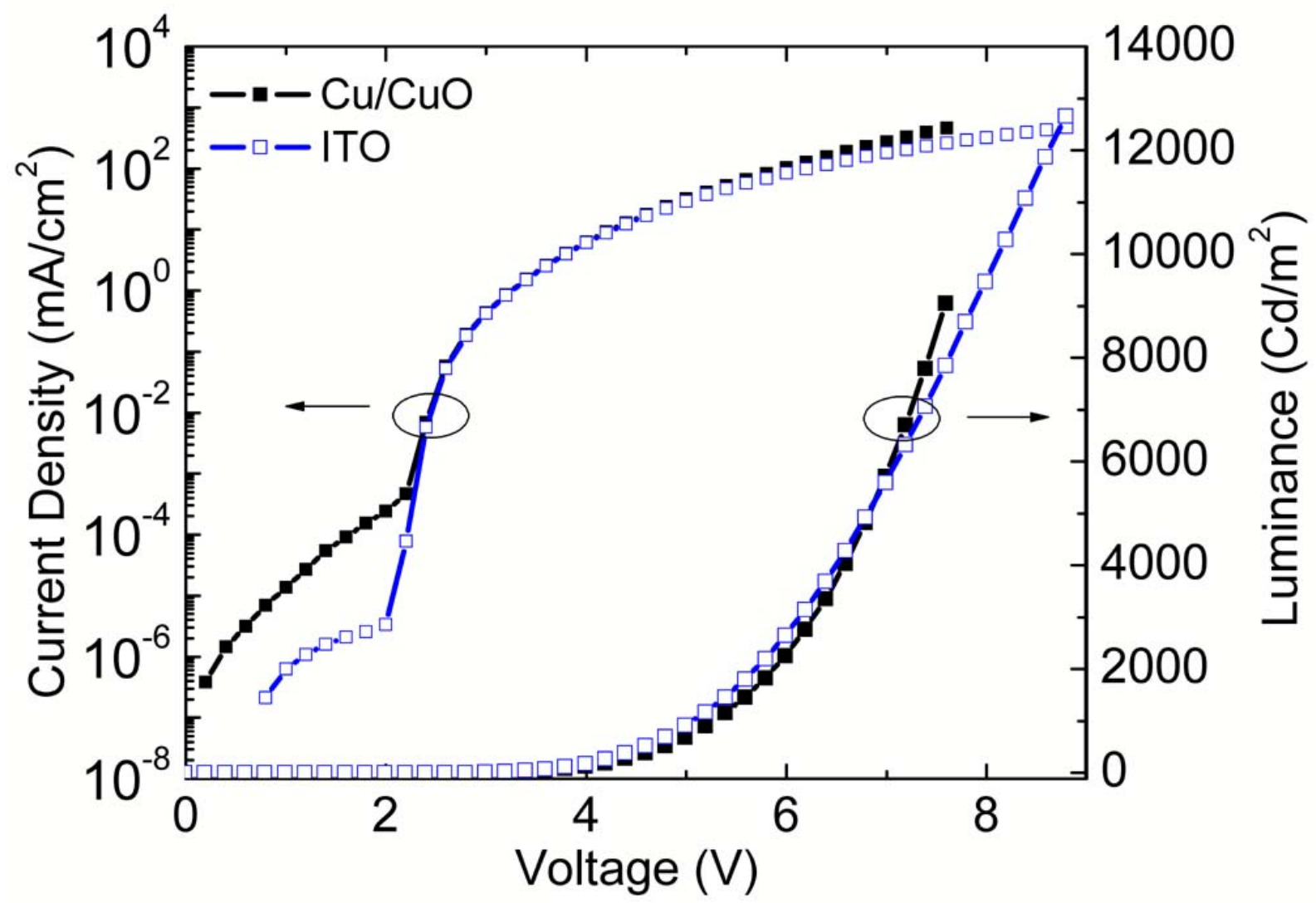

Figure 3.1. Current density vs. voltage and luminance vs. voltage for OLEDs made with UV-oxidized $\mathrm{Cu}$ and ITO anodes.

Previous reports of $\mathrm{Cu}$ oxide anodes $^{6}$ or anode modification layers ${ }^{5}$ have not distinguished any preferred $\mathrm{Cu}$ oxidation state. This distinction can be made, however, by examining both $2 \mathrm{p}_{3 / 2}$ XPS and LMM Auger spectra. ${ }^{9}$ XPS data are shown in figure 2a. The UV-ozone sample exhibits a satellite and main peak characteristic of $\mathrm{CuO}$. The heated sample has no satellite and a main peak consistent with either metallic $\mathrm{Cu}$ or $\mathrm{Cu}_{2} \mathrm{O}$. The Auger LMM peak position (Fig. 2b), however, confirms the presence of only $\mathrm{Cu}_{2} \mathrm{O}$ 
The thicknesses of UV-ozone oxide was found to plateau at $\sim 6 \mathrm{~nm}$ after 60 minutes of UV-ozone treatment, as determined by XPS sputter profiling and stylus profilometry of the sputter crater.

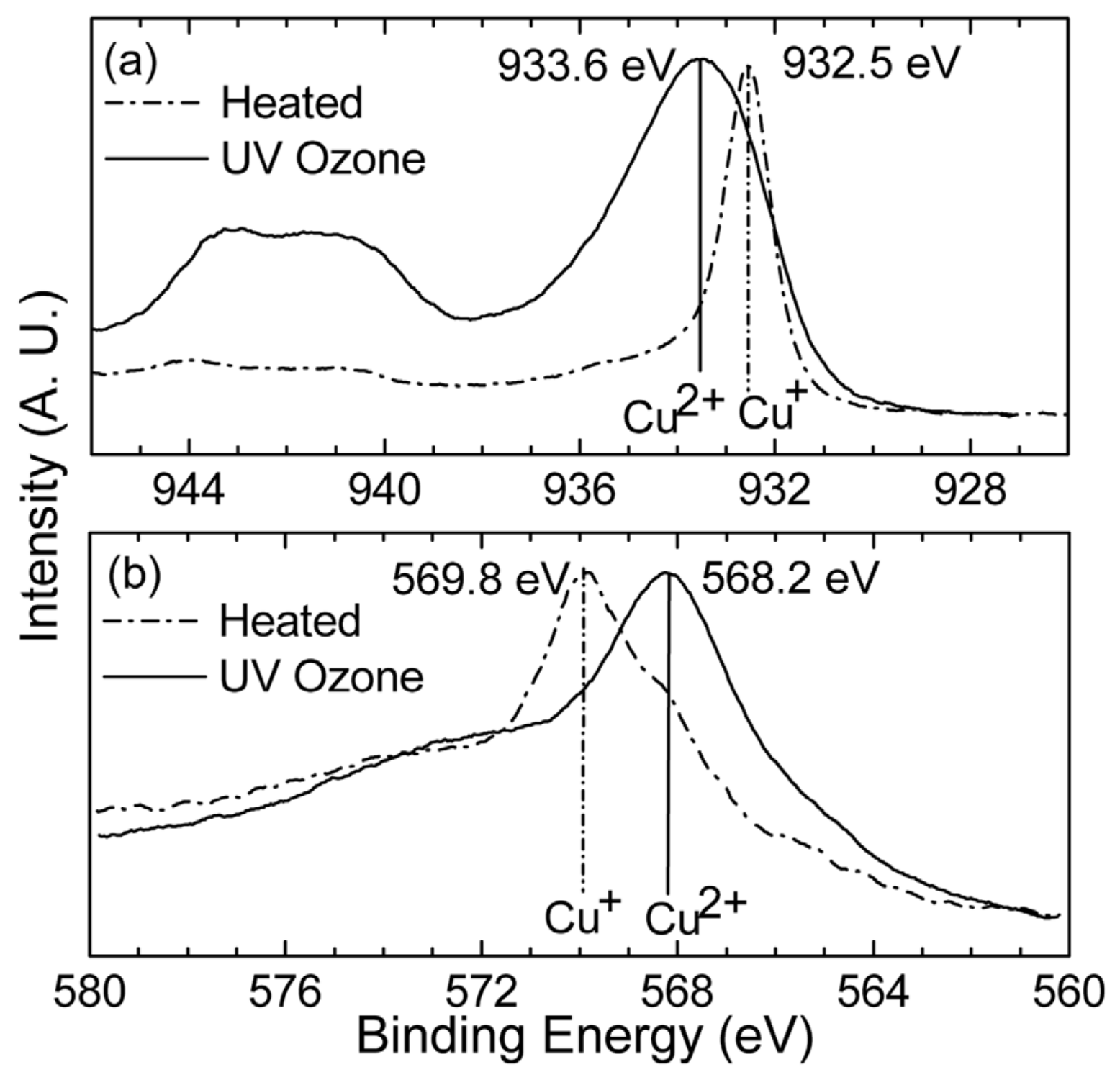

Figure 3.2. a) $\mathrm{Cu} 2 \mathrm{p}_{3 / 2} \mathrm{XPS}$ and b) CuLMM Auger spectra $(h v=1486.6 \mathrm{eV})$ for $5 \mathrm{~nm}$ $\mathrm{Cu}$ films heated at $100{ }^{\circ} \mathrm{C}$ for 60 minutes and UV-ozone treated for 60 minutes. 
In order to elucidate the hole injecting properties of $\mathrm{CuO}$ and $\mathrm{Cu}_{2} \mathrm{O}$, single-carrier devices were fabricated. Figure 3 shows the room temperature J-V characteristics of hole-only devices made with $\mathrm{Cu} / \mathrm{CuO}$ and $\mathrm{Cu} / \mathrm{Cu}_{2} \mathrm{O}$ anode structures. Qualitatively, it is seen that the $\mathrm{Cu} / \mathrm{CuO}$ anode exhibits a much larger hole-current. A useful model approximating charge injection into organic materials has been described by Scott and Malliaras, ${ }^{10,11}$ and has been used to fit the single-carrier device data. In this model, charge recombination at the organic interface due to carriers hopping within an image potential is used in combination with the principle of detailed balance to calculate the electric field dependence of thermionic injection. The field and temperature dependence of the injection current is given by:

$J=4 \psi^{2} N_{0} E \mu \exp \left(-\phi_{b} / k_{b} T\right) f^{1 / 2}$

where, $f$ is the reduced electric field,

$f=e^{3} E / 4 \pi \varepsilon k_{b}^{2} T^{2}$

and

$\psi(f)=f^{-1}+f^{-1 / 2}-f^{-1}\left(1+2 f^{1 / 2}\right)^{1 / 2}$

In the above equations, $E$ is the applied electric field, $\mu$ is the field dependent carrier mobility, $N_{0}$ is the density of chargeable states in the organic film, $\phi_{b}$ is the barrier height, $k_{b}$ is the Boltzmann constant, $T$ is the Kelvin temperature, and $\varepsilon$ is the dielectric constant of the organic material. 


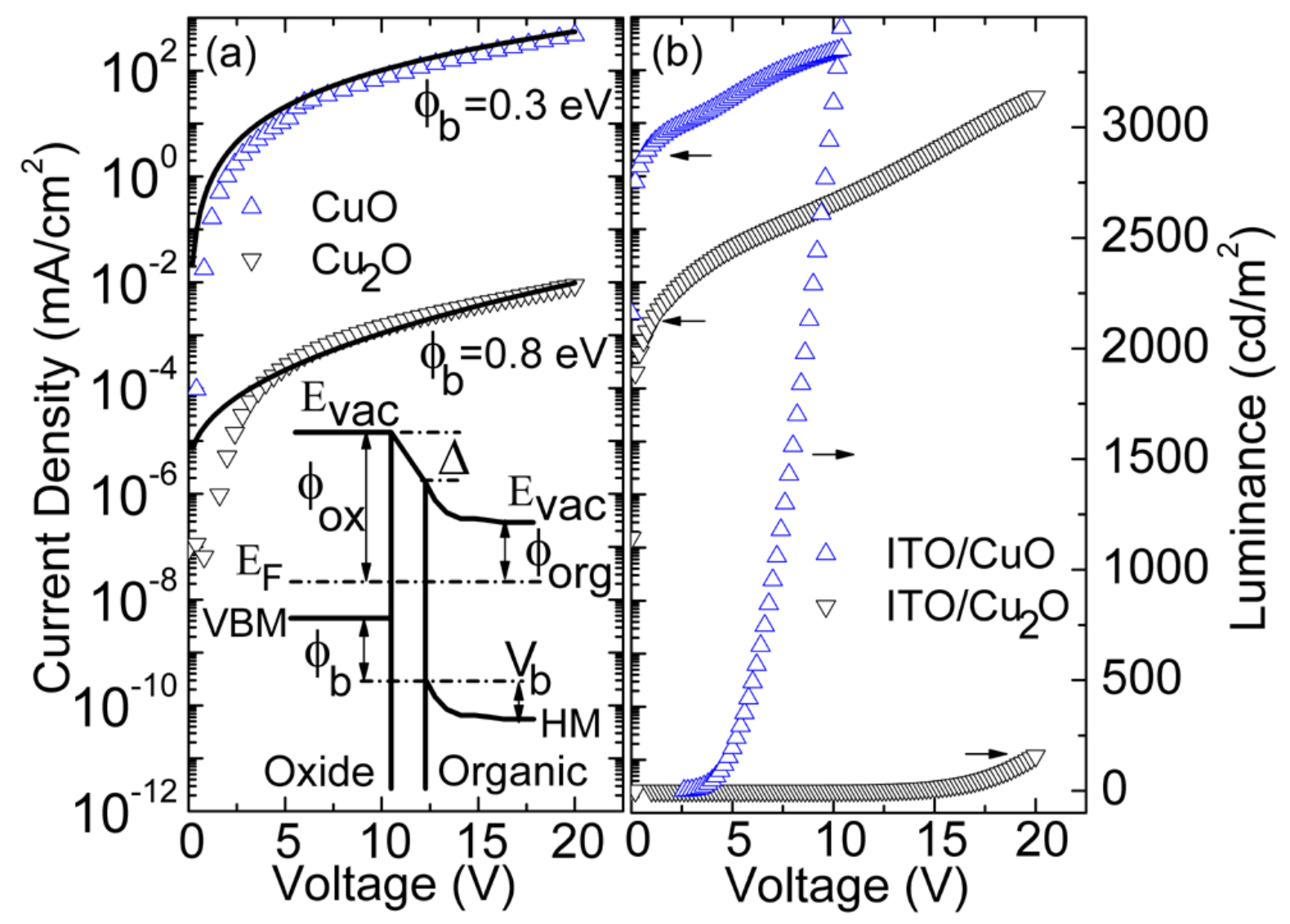

Figure 3.3. a) Current density vs. voltage for hole-only structures as follows: Anode/NPB $(500 \mathrm{~nm}) / \mathrm{Cu}$. The anodes used were $\mathrm{Cu} / \mathrm{CuO}$ and $\mathrm{Cu} / \mathrm{Cu}_{2} \mathrm{O}$. Fits to the Scott and Malliaras injection model are included as solid lines, along with $\phi_{b}$ values, see Ref. 10 and 11 . b) Current density vs. voltage and luminance vs. voltage (inset) for OLEDs made with $\mathrm{CuO}$ and $\mathrm{Cu}_{2} \mathrm{O}$ capped ITO anodes.

The field dependent mobility and relative permittivity for NPB deposited in our vacuum system was obtained through time-of-flight and capacitance-voltage measurements reported elsewhere ${ }^{12}$. The density of chargeable states in the highest occupied molecular orbital (HOMO) $\left(N_{0}=10^{21} \mathrm{~cm}^{-3}\right)$ is taken by assuming one state per molecule. Figure 3a shows fits to the single carrier device data. Barrier heights $\phi_{b}=0.3$ $\mathrm{eV}$ for the $\mathrm{CuO} / \mathrm{NPB}$ interface and $\phi_{b}=0.8 \mathrm{eV}$ for the $\mathrm{Cu}_{2} \mathrm{O} / \mathrm{NPB}$ interface were extracted. Figure $3 \mathrm{~b}$ shows $\mathrm{J}-\mathrm{V}$ and $\mathrm{L}-\mathrm{V}$ characteristics for OLEDs made using ITO 
modified with $5 \mathrm{~nm}$ of either oxide of $\mathrm{Cu}$. As expected from the single carrier devices, capping with $\mathrm{Cu}_{2} \mathrm{O}$ resulted in greatly reduced current density and luminance when compared with $\mathrm{CuO}$; this can be attributed to the reduction in hole-injection barrier height.

$\mathrm{X}$-ray and ultraviolet photoemission spectroscopies were used to investigate the electronic structure of the oxide/NPB interface for both types of oxides. This combination of techniques allows one to distinguish between interfacial dipole formation and band bending, in addition to possible charging. ${ }^{13,}{ }^{14}$ Films of NPB were deposited on the oxides by step-by-step deposition, while obtaining XPS and UPS spectra in situ after each deposition step. The final NPB thickness used for analysis was $12.8 \mathrm{~nm}$, as sample charging became significant after $25.6 \mathrm{~nm}$, as seen by large XPS peak shifts when switching the UPS photon flux on and off. Figure $4 \mathrm{a}$ and $4 \mathrm{~b}$ show He I valence band spectra for the NPB deposition sequence on $\mathrm{CuO}$ and $\mathrm{Cu}_{2} \mathrm{O}$ substrates. Linear fits of the substrate valence band features and backgrounds are used to determine the valence band maximum (VBM) positions relative to the Fermi level $\left(E_{f}\right)$. These relative positions, denoted $\Delta E_{v}$, are $0.1 \mathrm{eV}$ in the case of $\mathrm{CuO}$, and $0.3 \mathrm{eV}$ in the case of $\mathrm{Cu}_{2} \mathrm{O}$. With increasing NBP thickness, NPB's HOMO spectral feature becomes apparent. The relevant hole injection barrier is the energy difference between the oxide VBM and the HOMO maximum (HM) before band bending. $\mathrm{HM}$ is taken as the low binding energy cutoff of the HOMO feature. ${ }^{13,14,15}$ Referring to the inset of figure 3a, we have, $\phi_{b}=E_{H M}-V_{b}-\Delta E_{v}$ 
where $E_{H M}$ is the position of HM relative to $E_{f}$, and $V_{b}$ is the degree of band bending. At $12.8 \mathrm{~nm}$ NPB thickness, $E_{H M}$ is $0.9 \mathrm{eV}$ for the $\mathrm{CuO}$ system, and $1.1 \mathrm{eV}$ for the $\mathrm{Cu}_{2} \mathrm{O}$ system.

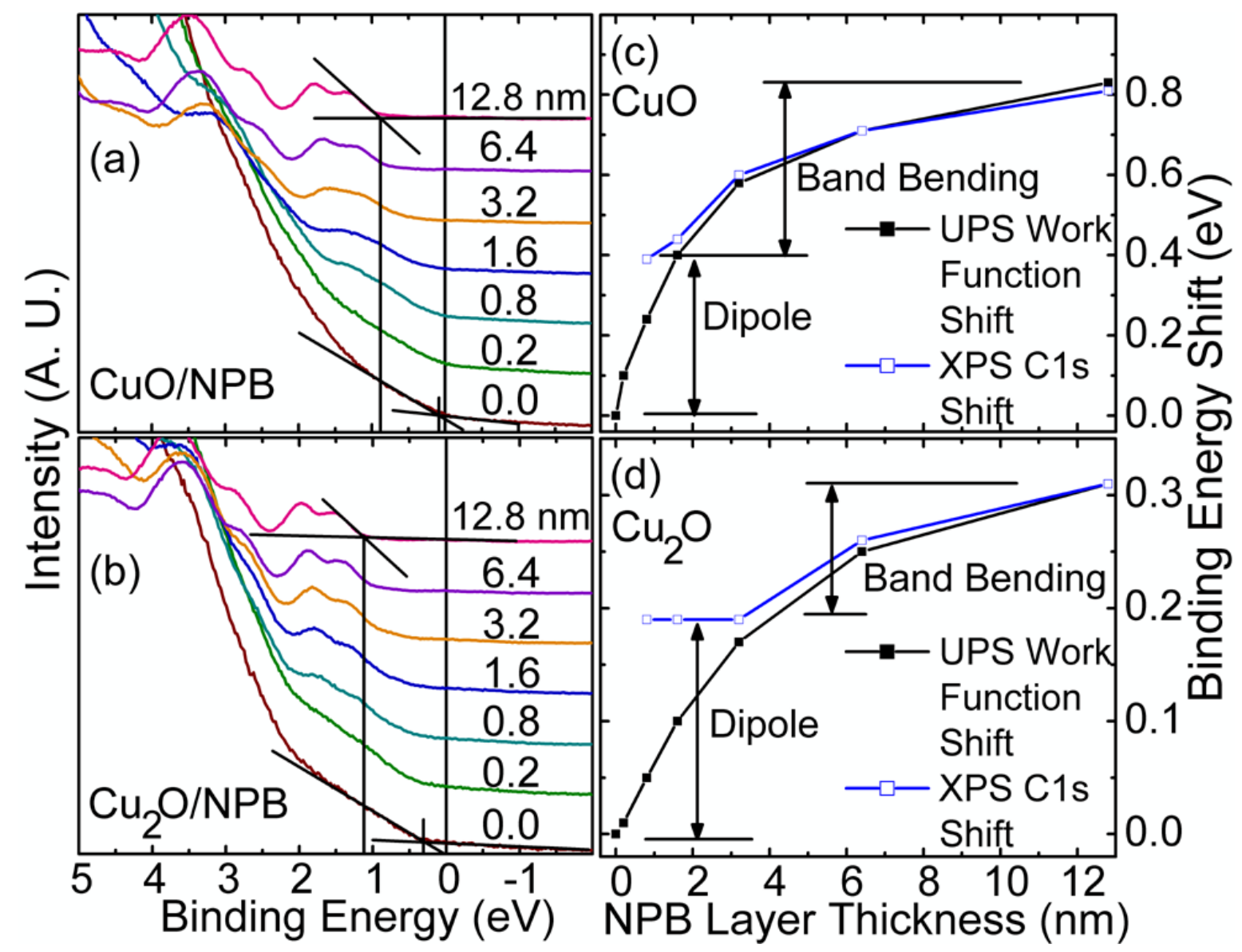

Figure 3.4. He I UPS valence band spectra for a) $\mathrm{CuO}$ and b) $\mathrm{Cu}_{2} \mathrm{O}$ substrates with sequential NPB deposition up to a thickness of $12.8 \mathrm{~nm}$. Work function shifts and $\mathrm{C} 1 \mathrm{~s}$ core level shifts vs. NPB thickness are plotted for c) $\mathrm{CuO}$ substrate and d) $\mathrm{Cu}_{2} \mathrm{O}$ substrate.

In order to determine the amount of band bending in the NPB, corresponding shifts in the C1s XPS peaks were monitored for both oxide systems. In addition, work function shifts were measured via UPS secondary cutoff. Figures $4 \mathrm{c}$ and $4 \mathrm{~d}$ show that at an NPB thickness of $12.8 \mathrm{~nm}$ the amount of band bending was $0.4 \mathrm{eV}$ and $0.1 \mathrm{eV}$ for the 
$\mathrm{CuO}$ and $\mathrm{Cu}_{2} \mathrm{O}$ systems, respectively. The work function of the $\mathrm{CuO}$ substrate was measured to be $5.3 \mathrm{eV}$, and that of the $\mathrm{Cu}_{2} \mathrm{O}$ substrate was $4.6 \mathrm{eV}$, agreeing with literature values ${ }^{16,17}$. Additionally, deviation of the C1s shift from the UPS work function shift at low NPB coverage for both material systems indicates the presence of an interface dipole, $\Delta .^{13}$ The values of $\Delta$ are found to be $0.4 \mathrm{eV}$ and $0.2 \mathrm{eV}$ for the $\mathrm{CuO}$ and $\mathrm{Cu}_{2} \mathrm{O}$ systems. Using Eq. 4, hole-injection barriers are calculated to be $0.4 \mathrm{eV}$ for the $\mathrm{CuO} / \mathrm{NPB}$ interface, and $0.7 \mathrm{eV}$ for the $\mathrm{Cu}_{2} \mathrm{O} / \mathrm{NPB}$ interface, in good agreement with the previous transport calculations.

\subsection{Conclusion}

In summary, it is found that $\mathrm{UV}$-ozone treated $\mathrm{Cu}$ acts as a suitable anode for organic light emitting diodes, imparting low driving voltage and high luminous output despite its moderate transparency. Low cost, high conductivity, easy patternability and low thermal budget make such ozone treated $\mathrm{Cu}$-based anodes attractive for use in commercial applications. Moreover, we have identified $\mathrm{CuO}$ as the oxidation state of $\mathrm{Cu}$ most suited for hole-injection into NPB. Transport modelling of single carrier devices yields calculated hole-injection barrier heights which harmonize well with the observed electronic structure investigated via photoemission, showing a significantly smaller barrier at the $\mathrm{CuO} / \mathrm{NPB}$ interface. Although this study has focused exclusively on holeinjection into $\mathrm{NPB}$, the $\mathrm{Cu} / \mathrm{CuO}$ system is a potential candidate for low junction resistance anode contacts for other organic materials. 


\section{Chapter 4. Aluminum doped zinc oxide for organic photovoltaics}

\subsection{Introduction}

Aluminum doped zinc oxide (AZO) was grown via magnetron sputtering as a low-cost alternative to indium tin oxide (ITO) for organic photovoltaics (OPV). Post deposition ozone treatment was found to play a critical role in enabling the use of AZO for $\mathrm{Cu}$-phthalocyanine $/ \mathrm{C}_{60}$ cells. Electrical conductivity of $\mathrm{AZO}$ increased upon exposure to ozone. Ozone treatment of AZO films resulted in devices with lower series resistance, increased open-circuit voltage, and power conversion efficiency double that of devices fabricated on untreated AZO. These improvements are explained through band alignment. Furthermore, cells fabricated using ozone treated AZO and standard ITO displayed comparable performance.

Organic photovoltaics (OPVs) have drawn increasing interest as a route to capture sunlight for low-cost renewable energy. Since Tang ${ }^{1}$ introduced the first donor-acceptor (DA) device more than a decade ago, power conversion efficiencies of OPVs have steadily risen, reaching efficiencies higher than $5 \%$ for small-molecule devices. ${ }^{2}$ Polymer-based photovoltaics show similar performance gains. ${ }^{3} \quad$ All photovoltaics, including OPVs, require the use of transparent conducting electrode materials in order to admit light into the active region as well as to collect charge. The cost of transparent conductive films is thus a critical component of the total OPV price. ITO is currently the de facto standard transparent conductive oxide (TCO) used in OPV technology due its high optical transparency, metallic conductivity, and high work function. Relatively little investigation has occurred involving the use of alternative TCOs for small-molecule OPV 
applications. This work is essential, however, given that ITO has become approximately ten times more expensive over the past 5 years due to diminishing indium resources; ${ }^{4}$ the cost of indium is only expected to grow with increasing demand from producers of photovoltaics on top of the existing flat-panel display industry.

The properties of $\mathrm{ZnO}$ doped with group three elements such as $\mathrm{Al}$ or $\mathrm{Ga}$ have been extensively investigated for use as low-cost TCOs. $\mathrm{ZnO}$ is a wide bandgap ( $3.3 \mathrm{eV})$, n-type semiconductor that can be produced by methods including pulsed laser deposition (PLD), chemical vapour deposition (CVD), spray pyrolysis, and magnetron sputtering. ${ }^{5}$ $\mathrm{ZnO}$ doped with aluminum (AZO) is well suited to PV applications owing to its high electrical conductivity and excellent optical transparency in the near infrared and visible regions. ITO-equivalent performance for phthalocyanine-based OPV devices fabricated on $\mathrm{ZnO}$ without the need for a buffer layer has not been demonstrated. ${ }^{4,6}$ One report of ITO-equivalent performance, however, has been made for oligothiphene-based cells. ${ }^{7}$ In this work, we show the importance of sputtering conditions and post-deposition ozone treatment of AZO prior to OPV fabrication. Furthermore, we show that ozone treated AZO is an effective ITO replacement for double-heterojunction phthalocyanine-based devices.

\subsection{Experimental}

OPV devices were fabricated on glass substrates cleaned in acetone, methanol and deionized water, followed by 15 minute ultraviolet (UV)-ozone treatment. Reference devices were fabricated on ITO coated glass $(15 \Omega / \square)$ cleaned in the same manner. AZO films were produced using dc magnetron sputtering in a BOC Edwards Auto 306 coating 
system equipped with an MDX 1.5 K DC Plasma Generator Power Supply. The base pressure was $\sim 10^{-7}$ Torr. A 3-inch diameter $\mathrm{ZnO}$ target doped with 2 wt.\% $\mathrm{Al}_{2} \mathrm{O}_{3}$ was sputtered at $50 \mathrm{~W}$ in a $5 \mathrm{mTorr}$ Ar atmosphere. Substrates were placed at 8, 12, 16 and 19 $\mathrm{cm}$ centre-to-centre distance from the target. The substrates were oriented perpendicular to the target, and were offset horizontally from the target center by $6 \mathrm{~cm}$. Anode lines were defined by photolithography using Shipley S1813 photoresist and 2\% $\mathrm{HCl}$ etchant solution. Sheet resistance measurements of all films were taken using a Keithley 2400 SourceMeter and four-point probes. Film thicknesses were measured using a KLA Tencor P-16+ stylus profilometer. Optical transmission and reflection spectra were taken using a Cary spectrophotometer equipped with an integrating sphere. Surface morphology was observed via scanning electron microscopy (SEM) and atomic force microscopy (AFM) in tapping mode. AZO films were treated by ex situ oxidation for 60 $\min$ by UV-ozone treatment.

Metal and organic films were thermally evaporated in separate chambers with base pressures of $\sim 10^{-7}$ Torr and $\sim 10^{-8}$ Torr, respectively. Film thicknesses were monitored using calibrated quartz crystal monitors. Organic solar cells were fabricated using copper phthalocyanine $(\mathrm{CuPc})$ and Buckminsterfullerene $\left(\mathrm{C}_{60}\right)$ as the donoracceptor (DA) system. The cell was finished using an exciton blocking layer of 1,3,5tris(2-N-phenylbenzimidazolyl) benzene (TPBI) and an aluminum cathode. The final device structure was as follows: Anode/CuPc (30 nm)/C60 (30 nm)/ TPBI(6 nm)/Al (80 $\mathrm{nm})$. The active area was $1 \mathrm{~mm} \times 2 \mathrm{~mm}$ for all devices. Device current density versus voltage $(\mathrm{J}-\mathrm{V})$ characteristics were measured using a Keithley 6430 sub-femptoamp meter under $100 \mathrm{~mW} / \mathrm{cm}^{2}$ simulated AM1.5G solar illumination. 


\subsection{Results and Discussion}

Figure 1a shows optical transmission spectra for untreated AZO films deposited at target-to-substrate distances of $8,12,16$ and $19 \mathrm{~cm}$. Figure $1 \mathrm{~b}$ shows electrical resistivity of AZO films as a function of target-to-substrate distance for as-deposited and ozonetreated samples. Film thicknesses were $98,164,248$, and $541 \mathrm{~nm}$ respectively owning to varying deposition rates within one deposition. These thicknesses were accounted for in the calculation of bulk resistivity. High transparency is observed throughout the visible spectrum, with an average transmission of $92 \%$ between 380 and $750 \mathrm{~nm}$ for the film deposited at $8 \mathrm{~cm}$. With decreasing target-to-substrate distance, the absorption edge of the AZO films moves towards lower wavelengths. We therefore infer by the Drude model $^{5}$ that shorter target-to-substrate distance resulted in higher free carrier concentration for AZO films deposited in our system. 

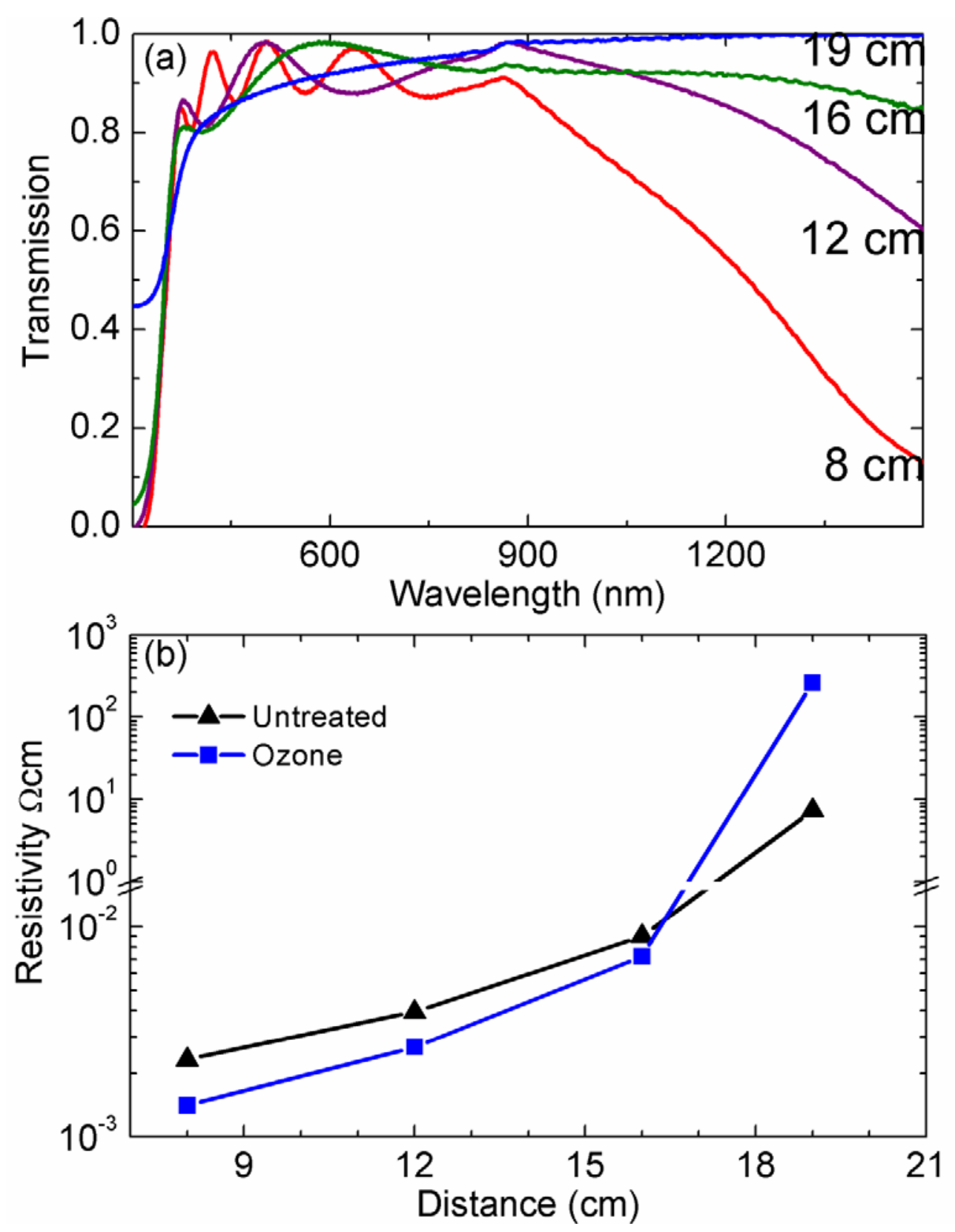

Figure 4.1. a) Optical Transmission vs. Wavelenth for untreated, DC sputtered AZO films deposited at $8,12,16$ and $19 \mathrm{~cm}$ target-to-substrate distances. b) Film resistivity for as-deposited and ozone treated AZO vs. target-tosubstrate distance.

Film resistivity increased monotonically with increasing target-to-substrate distance, as expected from optical measurements of carrier concentration. Significantly, 
ozone treatment lowered the resistivities of the most conductive AZO films. The resistivity of the film deposited at $8 \mathrm{~cm}$ was decreased by $40 \%$ from $2.3 \times 10^{-3}$ to $1.4 \times 10^{-3}$ $\Omega \mathrm{cm}$. At a distance of $19 \mathrm{~cm}$ from the target, the resistivity of as-deposited films increased abruptly by approximately three orders of magnitude. Interestingly, these films became much more resistive after ozone treatment. SEM images of as-deposited AZO films are shown in figure 2. With increasing target-to-substrate distance, grain sizes became progresssively smaller. A grain size of approximately $50 \mathrm{~nm}$ was observed for the most conductive film deposited at $8 \mathrm{~cm}$. The surface roughness of this film was found to be $6 \mathrm{~nm}$ by AFM. Increased conductivity at shorter range is attributable to increased carrier mobility (as expected from larger grain size and decreased grain boundary scattering), in addition to the higher carrier concentration observed optically. Since doping in $\mathrm{AZO}$ is thought to arise from $\mathrm{Al}$ subsitition on $\mathrm{Zn}$ cationic sites, ${ }^{8}$ we posit that the increase in conductivity with UV-ozone treatment for the most conductive films was due to a reduction in the number of oxygen vacancies in the AZO lattice, leading to reduced impurity scattering and higher electron mobility. No observable change in grain structure was seen by SEM after uv-ozone treatment. Lower carrier concentration with target-to-substrate distance indicates less $\mathrm{Al}$ incorporation into the $\mathrm{ZnO}$ lattice and subsequent segregation to grain boundaries or incorporation into $\mathrm{Al}_{2} \mathrm{O}_{3}$. For the least conductive film, the observed increase in resistivity with UV-ozone treatment was likely due to the reaction of segregated aluminum with oxygen, producing insulating $\mathrm{Al}_{2} \mathrm{O}_{3}$. 


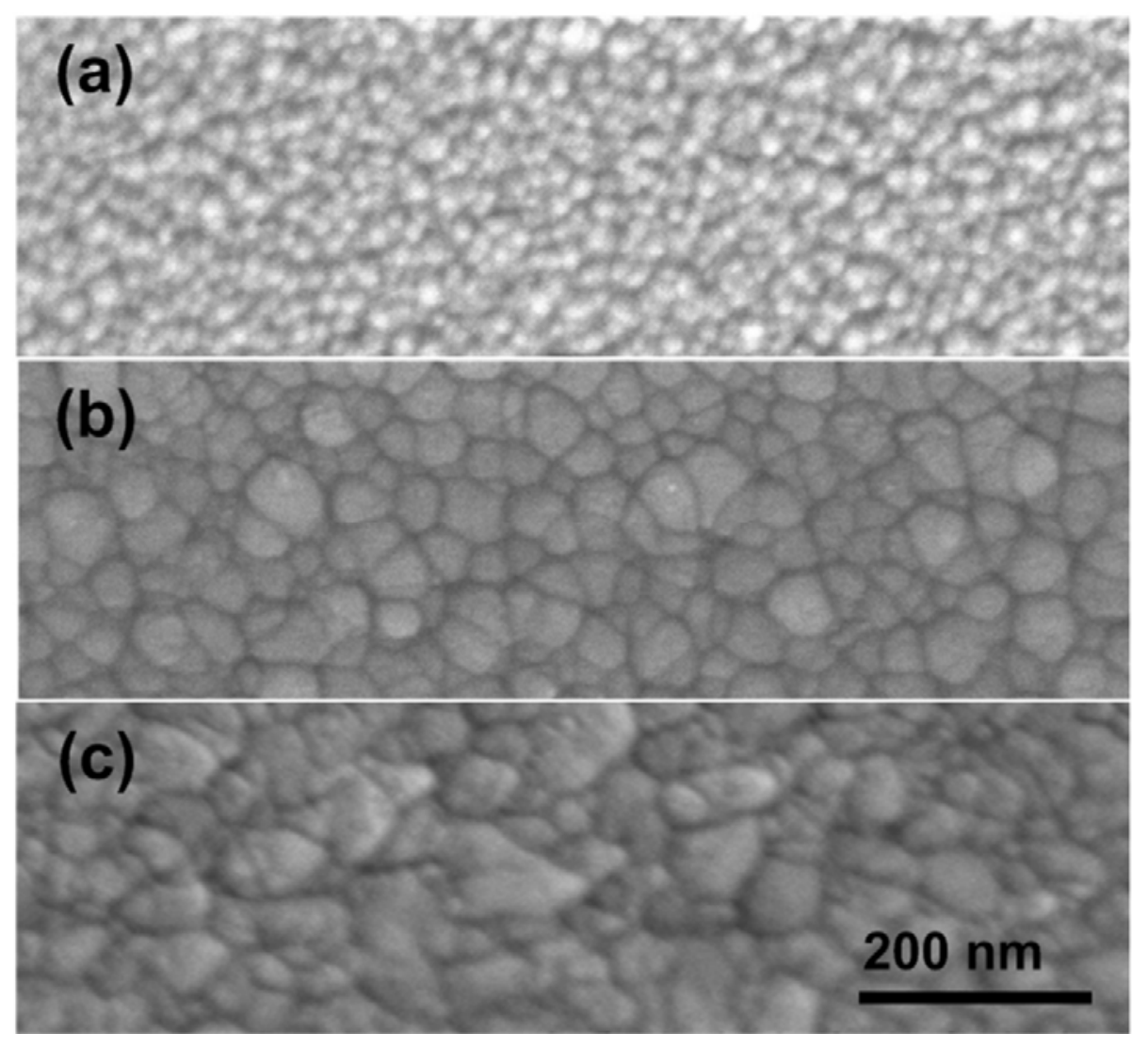

Figure 4.2. SEM micrographs of AZO films grown at target-to-substrate distances of a) $19 \mathrm{~cm}$, b) $16 \mathrm{~cm}, \mathrm{c}) 8 \mathrm{~cm}$.

Double heterostructure cells were prepared on the highest conductivity asdeposited (device A) and uv-ozone treated (device B) AZO films in a single deposition sequence. The sheet resistances of these films were 43 and $26 \Omega / \square$, respectively. Figure 3a shows the current-voltage characteristics of both types of device under $100 \mathrm{~mW} / \mathrm{cm}^{2}$ simulated solar illumination. A noticeable change in device performance occured following ozone treatment. Cell $\mathbf{B}$ exhibited higher open circuit voltage $\left(V_{O C}\right)$, and lower series resistance. A power conversion efficiency of $1.3 \%$ was attained for device $\mathbf{B}$ as compared to $0.7 \%$ for $\mathbf{A}$. The forward bias dark current of sample $\mathbf{B}$ was increased and 
the reverse bias current was decreased, indicating a reduced hole injection barrier and a larger barrier to electron injection for ozone treated AZO into CuPc. XPS secondary cutoff mesurements indicate an increase in work function from $4.2 \mathrm{eV}$ as deposited to 4.7 eV after in situ ozone treatment of unpatterned AZO.

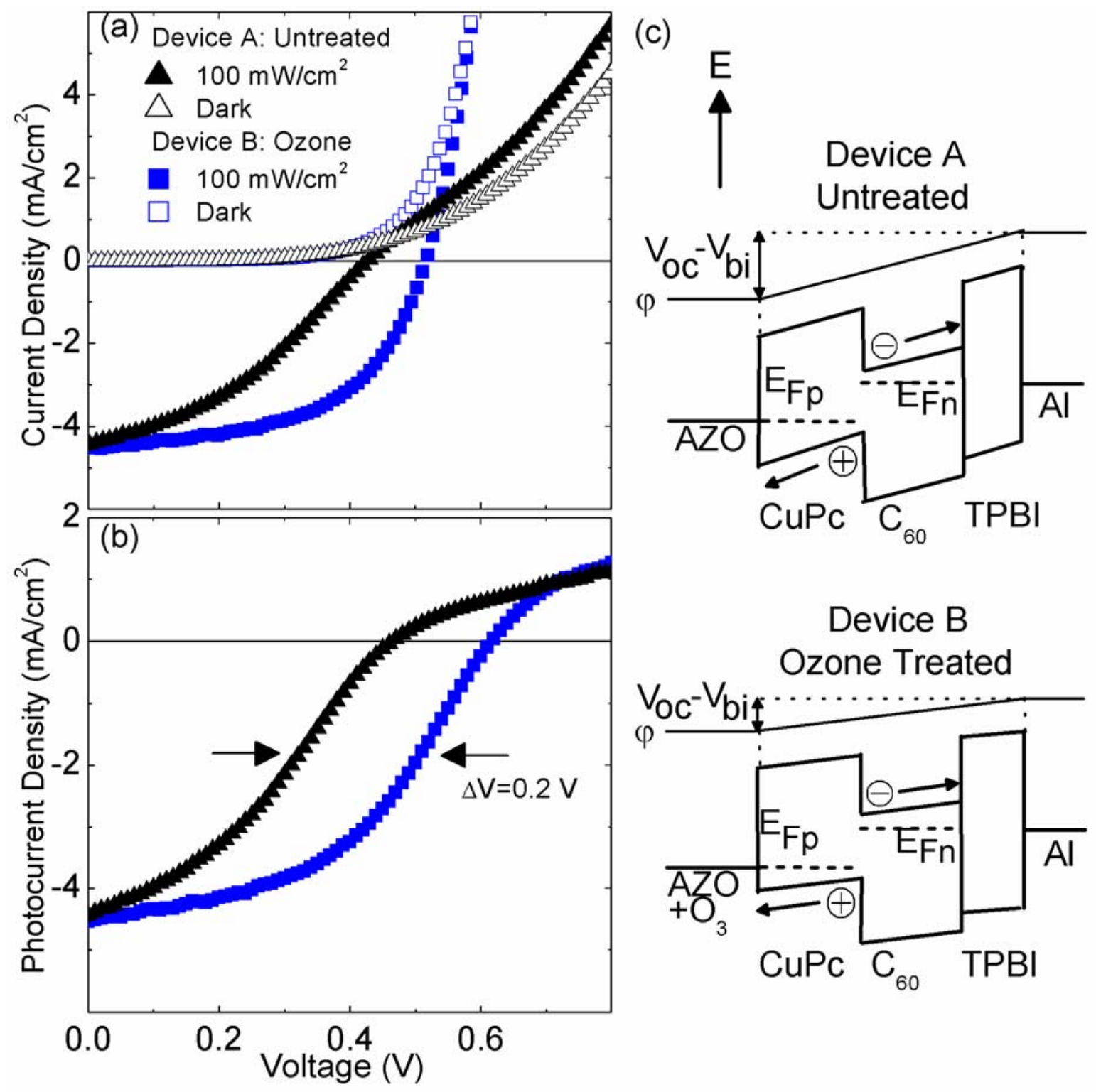

Figure 4.3. a) Current density and b) Photocurrent density vs. voltage for OPV devices made using as-deposited and ozone treated AZO. Current densities were measured under $100 \mathrm{~mW} / \mathrm{cm}^{2}$ and dark conditions. Photocurrent density at a specified voltage was calculated as the difference between device current densities measured under illuminated and dark conditions. 
Figure $3 \mathrm{~b}$ shows photocurrent-voltage curves for devices $\mathbf{A}$ and $\mathbf{B}$ obtained by subtracting dark from light current densities. Ozone treatment resulted in a clear shift of the photocurrent characteristic toward higher bias $(\Delta V=0.2 V)$. When taken with the aformentioned increase in forward bias dark current, this shift indicates an improved band alignment for ozone treated AZO, bringing the AZO Fermi level $0.2 \mathrm{eV}$ closer to CuPc's highest occupied molecular orbital (HOMO) upon contact. ${ }^{9}$ Consequently, device B has a larger built-in voltage $\left(V_{b i}\right)$. Figure $3 \mathrm{c}$ schematically shows the energy level alignment for samples A and B under open circuit conditions. Using the Einstein relation, ${ }^{10}$ the sum of drift and diffussion currents for electrons can be written in terms of the gradient in quasi-Fermi level, $\nabla E_{F n}$ :

$$
J_{n}(x)=e n(x) \mu_{n} \nabla E_{F n}(x)
$$

where $e$ is the charge of an electron, $n(x)$ is the carrier concentration, and $\mu_{n}$ is the electron mobility. ${ }^{11}$ A similar relation applies for holes. At $V_{O C}$, zero net current flows as drift balances diffusion and the quasi Fermi levels $E_{F n}$ and $E_{F p}$ are constant from the DA interface to the contacts as shown in figure $3 \mathrm{c}$. Furthermore, assuming no voltage drop across the contact interfaces, $V_{O C}$ equals the maximum splitting of the quasi Fermi levels across the solar cell. ${ }^{11}$

$$
V_{O C}=E_{F n}-E_{F p}
$$


The amount of splitting rises as the free carrier concentration in each layer rises. The electric field developed across the organics due to quasi Fermi level splitting under illumination counteracts the built-in field. The net potential gradient across the organics is thus the difference between $V_{O C}$ and $V_{b i}{ }^{12}$ This net potential gradient, which tends to confine free carriers to the DA interface, must be smaller in device $\mathbf{B}$ due to its larger $V_{b i}$, as shown in figure 3c. Less interface recombination due to reduced carrier accumulation at the DA interface, and improved exciton dissociation are therefore expected for device B. The resulting increase in free carrier concentration in device $\mathbf{B}$ leads to higher photocurrent close $V_{O C}$, as well as an increase in $V_{O C}$ itself due to greater quasi Fermilevel splitting. ${ }^{12}$

A sigmoidal $J-V$ characteristic was observed for device $\mathbf{A}$, but not for device $\mathbf{B}$. Approaching $0.4 \mathrm{~V}$, the electric field in the organics begins to oppose the flow of photogenerated free carriers, causing carrier accumulation at the at the DA interface. As mentioned, this effect is more pronounced for device $\mathbf{A}$ due its smaller built-in potential. Higher carrier concentration at the DA interface increases recombination and lowers the observed photocurrent. Concurrently, holes are being injected into $\mathrm{CuPc}$ from the AZO electrode. Due to a larger hole injection barrier for device $\mathbf{A}$, the forward current remains low. As the forward bias is further increased, holes begin to overcome the injection barrier, driving a forward current to complete the sigmoidal JV characteristic.

In order to demonstrate ozone-treated $\mathrm{AZO}$ as an ITO-alternative, devices employing AZO (device C) and ITO (device D) anodes were fabricated in a single deposition sequence. Figure 4 shows $J-V$ charactreristics of devices $\mathbf{C}$ and $\mathbf{D}$. 
Approximately equivalent performance was achieved by devices $\mathbf{C}$ and $\mathbf{D}$, with power conversion efficiencies matching within $10 \%$. The measured short circuit currents were nearly identical, from which we may conclude that there was little change in the optical field distribution, absorption of light in the active region, or in charge collection efficiency. Interestingly, devices made with AZO exhibited higher open circuit voltages than did those made with ITO. Table 1 compares relevent performance parameters for all devices. Reciprocal slopes of $J-V$ relations at $V_{O C}$ are used used to compare the series resistances, $R_{S}$, of the devices. ${ }^{13}$

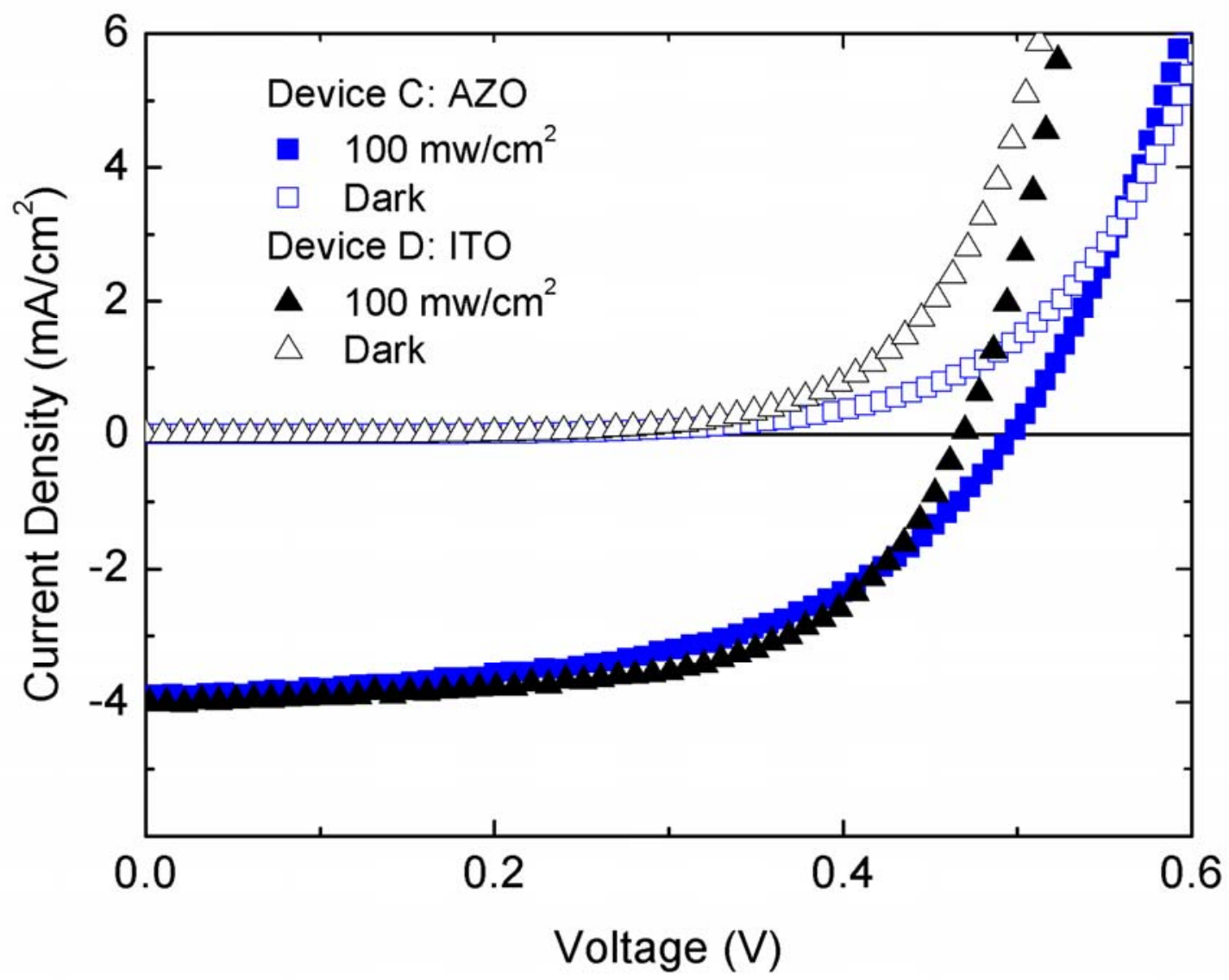

Figure. 4.4. Current density at $100 \mathrm{~mW} / \mathrm{cm}^{2}$ and dark illumination levels vs. voltage for OPV cells made using ozone treated AZO as well as ITO. 
Table 4.1. Open circuit voltage $V_{\mathrm{OC}}$, short circuit current density $J_{\mathrm{SC}}$, fill factor FF, Power Conversion Efficiency $\eta_{\mathrm{P}}$, and the calculated series resistance $\boldsymbol{R}_{\mathrm{S}}$ of all cells.

\begin{tabular}{llllllll}
\hline \hline Experiment & Device & Anode & $V_{\mathrm{OC}}$ & $J_{\mathrm{SC}}$ & $\mathrm{FF}$ & $\eta_{\mathrm{P}}$ & $R_{\mathrm{S}}$ \\
& & & $(\mathrm{V})$ & $\left(\mathrm{mA} / \mathrm{cm}^{2}\right)$ & & $(\%)$ & $\left(\Omega \mathrm{cm}^{2}\right)$ \\
\hline 1 & $\mathrm{~A}$ & $\mathrm{AZO}$ & 0.42 & 4.46 & 0.37 & 0.7 & 65 \\
& $\mathrm{~B}$ & $\mathrm{AZO}\left(\mathrm{O}_{3}\right)$ & 0.50 & 4.53 & 0.55 & 1.3 & 19 \\
\hline 2 & $\mathrm{C}$ & $\mathrm{AZO}\left(\mathrm{O}_{3}\right)$ & 0.49 & 3.96 & 0.53 & 1.0 & 24 \\
& $\mathrm{ITO}$ & 0.46 & 4.04 & 0.60 & 1.1 & 18 \\
\hline \hline
\end{tabular}

\subsection{Conclusion}

In sum, we have shown that ozone treated AZO is an effective ITO alternative material for CuPc-based organic photovoltaics. The optical transparency and conductivity of AZO was found to vary considerably with target-to-substrate distance. Optical transmission of $>90 \%$ and resistivity of $1.4 \times 10^{-3} \Omega \mathrm{cm}$ were achieved. Treating AZO films with UV-generated ozone resulted in improved conductivity. OPV cells fabricated on ozone treated AZO outperformed cells fabricated on as-deposited AZO, showing higher $V_{O C}$, fill factor, and power conversion efficiency. These improvements were explained through band alignment under $V_{O C}$ conditions employing quasi Fermi-level splitting. Finally, devices prepared with ozone treated AZO and ITO anodes were compared. Equvalent performance was obtained, showing low series resistance, high fill factor and power conversion efficiencies matching within $10 \%$. 


\section{Chapter 5. Transparent Conductive Oxides for Organic Photovoltaics}

\subsection{Introduction}

Fluorine doped tin oxide (FTO) and aluminum doped zinc oxide (AZO) were systematically investigated as alternatives to indium tin oxide (ITO) for canonical poly(3hexylthiophene $)(\mathrm{P} 3 \mathrm{HT})+[6,6]$-phenyl-C61 butyric acid methyl ester $(\mathrm{PCBM})$ polymer bulk heterojunction (BHJ) solar cells. Devices made with FTO performed twice as well as devices made with ITO, establishing FTO as a suitable, low-cost ITO replacement. Ozone treatment was shown to be a critical enabling element for both FTO and AZO. Xray photoelectron spectroscopy (XPS) and device characteristics were used to explain the effect of ozone treatment and the origin of open circuit voltage.

Successful development of efficient, low cost organic photovoltaic devices (OPVs) will have sweeping implications for worldwide energy production. Since Tang first introduced organic donor-acceptor OPV devices over a decade ago, ${ }^{1}$ power conversion efficiencies have risen above $5 \%$ for both polymer and small molecule based devices. ${ }^{2}$ Lifetimes of more than 10,000 hours have also been recently demonstrated. ${ }^{3}$ The use of sprayable or printable photoactive polymer materials offers inherent cost savings needed for solar energy adoption in the competitive marketplace. In addition to organic materials, transparent conductors comprise one of the major cost drivers for organic solar cells. Indium Tin oxide (ITO) remains the de facto standard transparent conducting oxide (TCO) used in OPV cells due to its combination of high optical transparency, high work function, and metallic conductivity. ${ }^{4}$ The cost of ITO, however, 
is expected to increase substantially due to the rarity of Indium base metal combined with surging market demand arising from flat panel displays.

In this work, fluorine tin oxide (FTO) and aluminum doped zinc oxide (AZO) are systematically examined as ITO-replacement materials for canonical poly(3hexylthiophene) $(\mathrm{P} 3 \mathrm{HT})+[6,6]$-phenyl-C61 butyric acid methyl ester (PCBM) polymer bulk heterojunction $(\mathrm{BHJ})$ solar cells. TCO replacement materials have been identified as an area of strategic research; ${ }^{5}$ nevertheless, relatively few studies of alternative TCO materials for OPVs have been published to date. ${ }^{6-10}$

Both FTO and AZO possess high electrical conductivity and optical transparency. FTO can be produced cheaply via spray pyrolysis and is typically used for dye sensitized solar cells. ${ }^{11}$ AZO can be produced by various means, including DC sputtering, and requires no high temperature annealing. ${ }^{12} \mathrm{We}$ demonstrate a doubling of OPV performance with the use of ozone treated FTO as opposed to a standard ITO anode without the need for a buffer layer. We identify ozone surface treatment as an essential enabling element for both FTO and AZO anodes, and explain the effect of ozone treatment using x-ray photoelectron spectroscopy (XPS). Finally, an explanation for the origin of open circuit voltage is proposed based on OPV device characteristics and XPS work function measurements. 


\subsection{Experimental}

OPV devices were fabricated on glass substrates cleaned in acetone, methanol and deionized water, followed by 15 minute ultraviolet (uv)-ozone treatment. Reference devices were fabricated on ITO coated glass substrates $(15 \Omega / \square)$ purchased from Colorado Concept Coatings Inc. and cleaned in the same manner. AZO films $(90 \Omega / \square)$ were produced using de magnetron sputtering in a BOC Edwards Auto 306 coating system equipped with an MDX 1.5 K DC Plasma Generator Power Supply. The base pressure was $\sim 10^{-7}$ Torr. A 3-inch diameter $\mathrm{ZnO}$ target doped with 2 wt.\% $\mathrm{Al}_{2} \mathrm{O}_{3}$ was sputtered at $50 \mathrm{~W}$ in a $5 \mathrm{mTorr}$ Ar atmosphere. FTO coated glass $(25 \Omega / \square)$ purchased from Solaronix Inc., was used following cleaning as per above. Sheet resistance measurements of all films were taken using a Keithley 2400 SourceMeter and four-point probes. Film thicknesses were measured using a KLA Tencor P-16+ stylus profilometer. Optical transmission spectra were taken using a Cary spectrophotometer. Surface morphology was observed via scanning electron microscopy (SEM) and atomic force microscopy (AFM) in tapping mode. XPS measurements were performed using a PHI 5500 system with monochromated $\mathrm{Al} \mathrm{K}_{\alpha}$ X-rays $(1486.6 \mathrm{eV})$. All spectra were calibrated by referencing to the Fermi edge of sputtered Au. ITO, AZO, and FTO films were treated by ex situ uv-ozone for $60 \mathrm{~min}$.

PCBM (17mg/mL):P3HT(17mg/mL) solution was prepared in 1,2Dichlorobenzene in a nitrogen-filled glove box, then stirred in dark for 8 hours at $50^{\circ} \mathrm{C}$. This solution was spin-coated on the various TCO substrates at $500 \mathrm{rpm}$ for $9 \mathrm{~s}$, then at $1100 \mathrm{rpm}$ for $45 \mathrm{~s}$. The polymer layer was dried for 24 hours at room temperature in a 
glove box, and the resulting film thickness was found to be $65 \mathrm{~nm}$. Lithium fluoride and aluminum films were thermally evaporated in a vacuum chamber with base pressure $\sim 10^{-}$

${ }^{7}$ Torr. Circular aluminum cathodes were used to define a device active area of $4.45 \mathrm{~mm}^{2}$ in all cases. Film thicknesses were monitored using a calibrated quartz crystal monitor. The final device structure was as follows: Anode/ PCBM:P3HT (65 nm)/ LiF (1 nm) )/Al $(80 \mathrm{~nm})$. Device current density versus voltage $(\mathrm{J}-\mathrm{V})$ characteristics were measured using a Keithley 6430 sub-femptoamp meter under $100 \mathrm{~mW} / \mathrm{cm}^{2}$ (1 sun) simulated AM1.5G solar illumination.

\subsection{Results and Discussion}

As will be shown below, ozone treatment of FTO and AZO alternatives is essential for efficient BHJ device performance. It is well known that treatment of ITO with ozone serves to increase its work function and improve the performance of devices made therewith. Importantly, we find that a similar increase in work function results for both FTO and AZO films upon treatment. Figure 1a shows the XPS secondary cutoffs for treated and untreated $\mathrm{AZO}$ and FTO. In both cases, ozone treatment was found to increase the work function of the TCO by $0.4 \mathrm{eV}$, resulting in a $0.4 \mathrm{eV}$ shift in the secondary cutoffs towards lower binding energy. A common explanation for this increase in work function is band bending due to carrier accumulation at the oxide surface ${ }^{13}$. Band bending would cause both a core level shift and a change in work function. ${ }^{14,15}$ Figure 1b shows the $\mathrm{Sn} 3 \mathrm{~d}_{5 / 2}$ and $\mathrm{Zn} 2 \mathrm{p}_{3 / 2}$ spectra for ozone treated and as-deposited FTO and AZO. No appreciable core level shifts are observed after ozone treatment. Therefore, band bending alone does not explain the increases in work function. We posit the formation of 
dipole layers arising from oxygen termination of the TCO surfaces during ozone treatment as the cause of the work function increase. Such dipole layers would raise the apparent material work function without creating a depletion region that would cause a core level shift. ${ }^{14,15}$

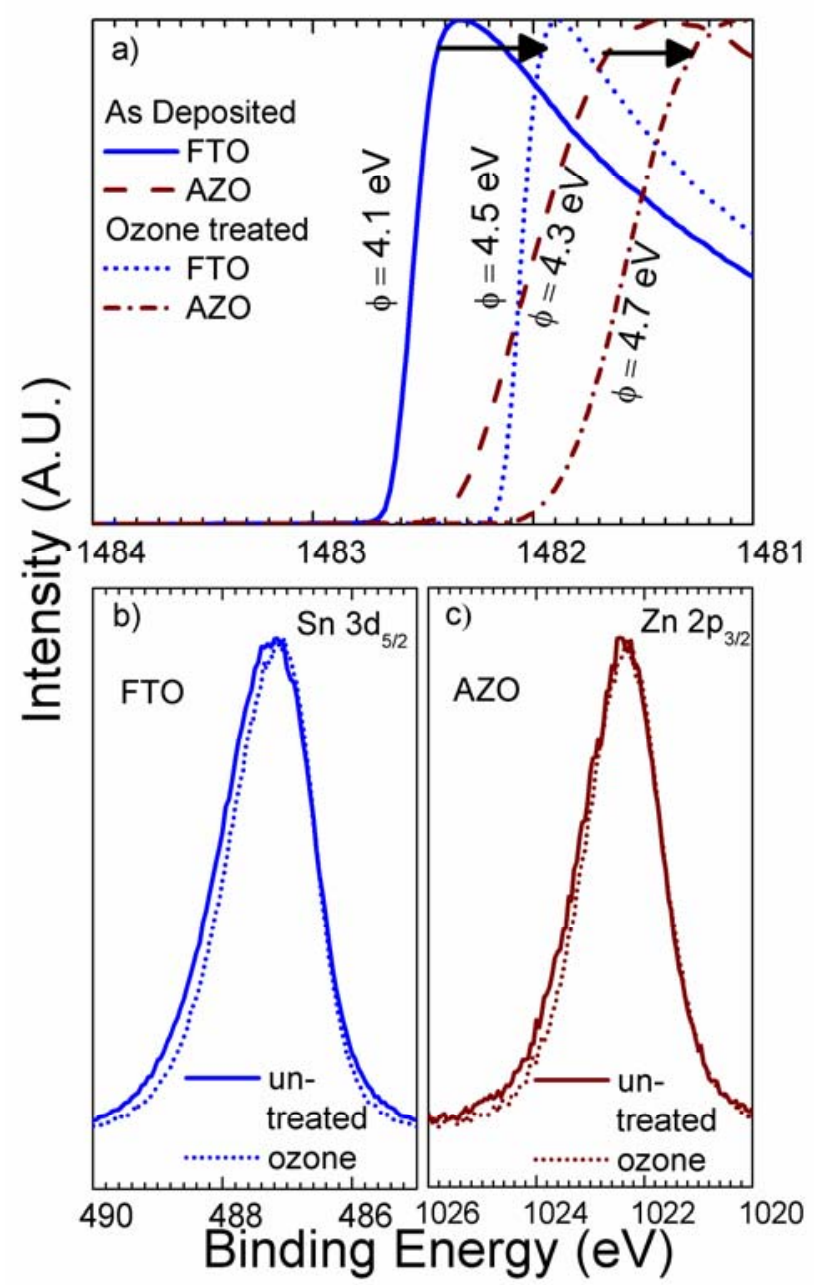

Figure 5.1. Secondary cutoffs (a) and core level shifts (b) for ozone treated and untreated AZO and FTO.

Figure 2a shows the $J V$ characteristics of BHJ cells made with ozone treated FTO, AZO and ITO measured under 1 sun illumination. Significantly, the FTO device achieved a power conversion efficiency almost twice that of the other cells. Ozone treated FTO is 
therefore suitable as an inexpensive and superior anode replacement material for PCBM:P3HT based devices without the need for a buffer layer. Table I shows the relevant parameters for devices shown in figure 3a.The FTO device exhibited much higher shunt resistance, $R_{\text {shunt }}$, and short circuit current, $J_{S C}$, than the other devices. A low $R_{\text {shunt }}$ is detrimental, and can arise from the leakage of photogenerated electrons to the anode during device operation; this leakage current subsequently reduces $J_{S C}$ as electrons and holes recombine at the anode. We therefore conclude that ozone treated FTO provides a more suitable barrier to photogenerated electrons when compared to AZO and ITO.

TABLE 5.1. Open circuit voltage $V_{O C}$, short circuit current density $\mathbf{J}_{S C}$, fill factor FF, Power Conversion Efficiency $\eta_{P}$, calculated series resistance $R_{S}$, and shunt resistance $R_{\text {shunt }}$ of cells fabricated on various transparent conductive anodes.

\begin{tabular}{llllllll}
\hline \hline Device & Anode & $\begin{array}{l}V_{\text {OC }} \\
(\mathrm{V})\end{array}$ & $\begin{array}{l}J_{\text {SC }} \\
\left(\mathrm{mA} / \mathrm{cm}^{2}\right)\end{array}$ & $F F$ & $\begin{array}{l}\eta_{\mathrm{P}} \\
(\%)\end{array}$ & $\begin{array}{l}R_{\mathrm{S}} \\
\left(\Omega \mathrm{cm}^{2}\right)\end{array}$ & $\begin{array}{l}R_{\text {Shunt }} \\
\left(\Omega \mathrm{cm}^{2}\right)\end{array}$ \\
\hline A & FTO & 0.55 & 9.45 & 0.54 & 2.79 & 2.26 & 1031 \\
$\mathrm{~B}$ & AZO & 0.45 & 5.60 & 0.49 & 1.24 & 3.47 & 257 \\
$\mathrm{C}$ & ITO & 0.55 & 5.45 & 0.47 & 1.40 & 8.21 & 299 \\
\hline
\end{tabular}

Figure $2 \mathrm{~b}$ shows device $J V$-characteristics for both ozone treated and untreated samples. Prior to ozone treatment, AZO acted as an Ohmic contact for electrons to the polymer blend. In this case, the cell behaved as an electron-only device. The untreated FTO device exhibited poor short circuit current and open circuit voltage, $V_{O C}$. Ozone treatment is therefore essential to device performance when using alternative TCO anode materials. 


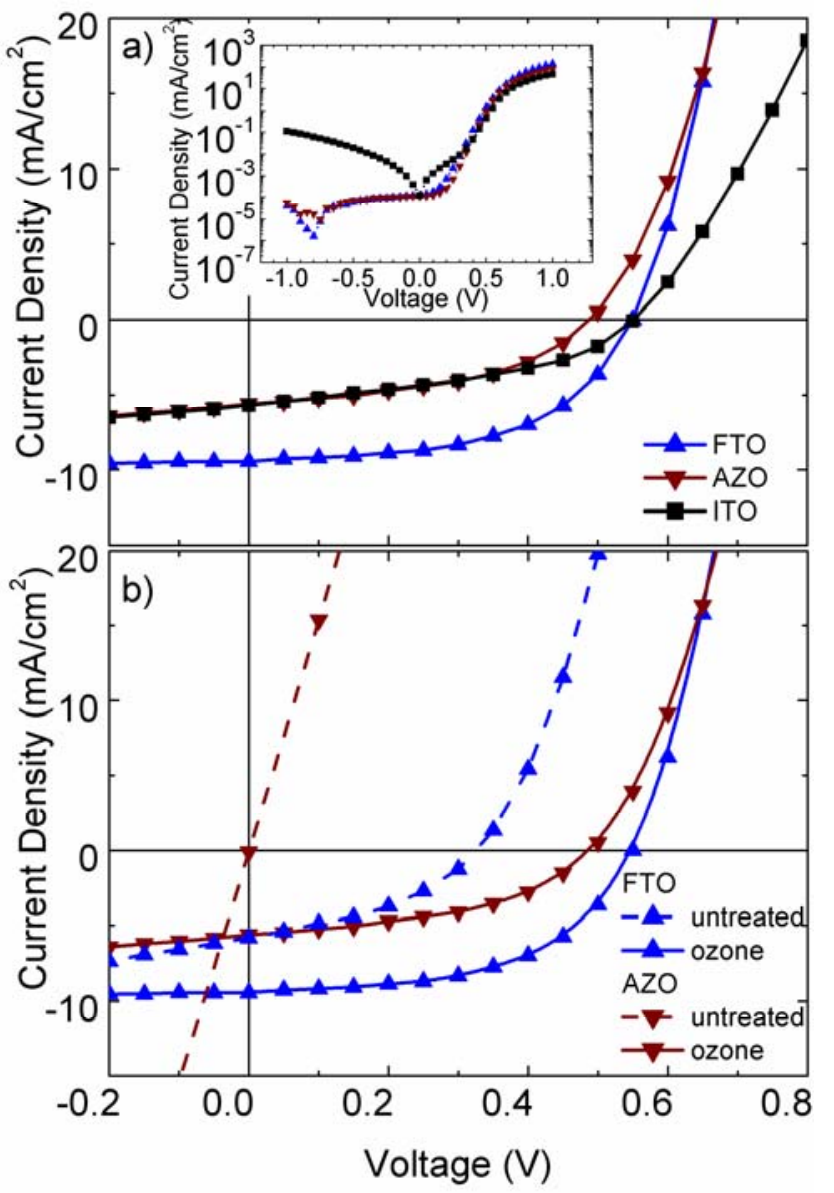

Figure 5.2. a) $J V$ curves for PCBM:P3HT solar cells under $100 \mathrm{~mW} / \mathrm{cm}^{2}$ AM1.5G illumination and dark (inset). b) $J V$ curves for PCBM:P3HT devices fabricated on untreated and ozone treated FTO and AZO under 100 $\mathrm{mW} / \mathrm{cm}^{2}$ AM1.5G illumination

The present study of alternative transparent anodes with dramatically different work functions offers a perspective into the origin of open circuit voltage in BHJ devices. Consider an idealized BHJ device with a photoactive region sandwiched between two barrier-free contacts. Within such an idealized device, electron current can be calculated from the gradient in quasi Fermi level, $\nabla E_{F n}$, using the Einstein relation.

$$
J_{n}(x)=J_{D R I F T}+J_{D I F F U S I O N}=e n(x) \mu_{n} \nabla E_{F n}(x)
$$


where $e$ is the charge of an electron, $n(x)$ is the carrier concentration, and $\mu_{n}$ is the electron mobility. ${ }^{16}$ A similar relation applies for holes. At $V_{O C}$, current flow is zero, and the quasi Fermi levels $E_{F n}$ and $E_{F p}$ are constant. Assuming no voltage drops at the contact interfaces, $V_{O C}$ equals the maximum splitting of the quasi Fermi levels across the solar cell. $^{16}$

$$
V_{O C}=E_{F n}-E_{F p}
$$

Due to the homogeneity of the active region in a bulk heterojunction, the concentration of charges being generated is approximately uniform throughout the photoactive layer. Although concentration gradients may exist locally in PCBM and P3HT phases, no significant concentration gradients of photogenerated charge are expected over the entire thickness of the photoactive region. Consequently, we expect the device current to be dominated by the drift current.

$$
J_{D R I F T}=e\left(n \mu_{n}+p \mu_{p}\right) E
$$

At the $V_{O C}$ condition, zero net current flows. Therefore, we have that $J_{D R I F T}$ is approximately nil, implying zero field across the device according to equation 3 . Figure 3a shows the potential difference developed across a BHJ device due to quasi Fermi level splitting under illumination. For zero field and zero drift current, we must have that

$$
V_{b i}-V_{O C} \approx 0
$$


Any further quasi Fermi level splitting will introduce a nonzero electric field, yielding a nonzero drift current. Therefore, the open circuit voltage cannot exceed the built-in potential significantly in this idealized situation.

a)

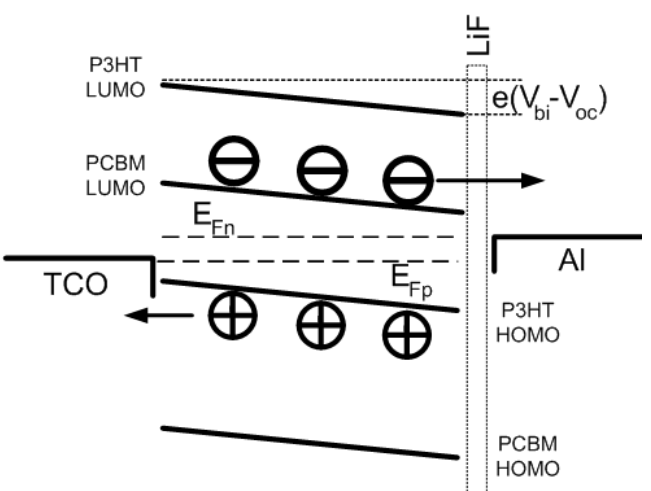

b)

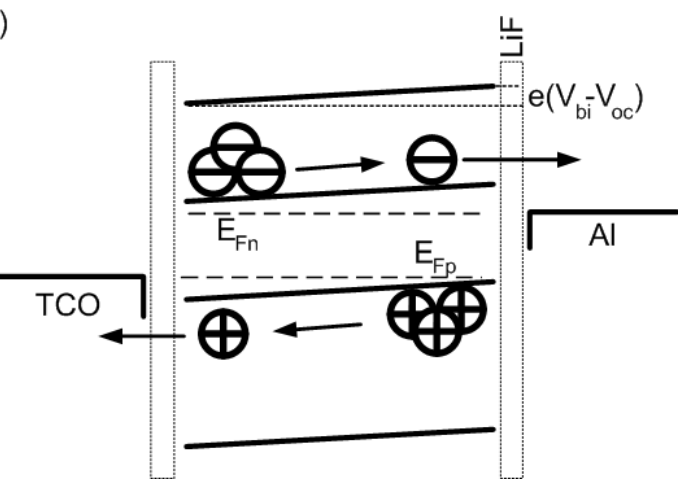

Figure 5.3. a) Schematic band alignment of a bulk heterojunction device under the condition $\mathrm{V}_{\mathrm{OC}}<\mathrm{V}_{\mathrm{bi}}$. b) Band alignment of a BHJ device with an electron blocking anode under the condition $\mathrm{V}_{\mathrm{OC}}>\mathrm{V}_{\mathrm{bi}}$.

Turning to our devices, we see that the device made with ozone treated FTO exhibited a $V_{O C}$ larger than $V_{b i}$ calculated from the work function difference of the FTO and $\mathrm{Al}$ contacts. Furthermore, the FTO device showed higher $V_{O C}$ than the device made with AZO, despite having a lower built-in potential. The reason for this apparent discrepancy lies in the ability of the various TCOs to block electrons from exiting the active region, which was not taken into account in the discussion above. As the forward 
bias is increased beyond $V_{b i}$, photogenerated electrons will tend to move towards the anode. If there were no barrier to electron flow out of the device, a forward current would result, and the open circuit condition would no longer exist. However, if a barrier to electron flow is imposed at the anode, electrons will tend to accumulate at the anode contact. This scenario is depicted in figure $3 \mathrm{~b}$. An entropic diffusion current to oppose the drift current will thus develop, allowing a zero current condition at higher bias. Thus, an anode contact which tends to block electron flow can cause $V_{O C}$ to exceed $V_{b i}$. Devices which possess high $V_{b i}$ are capable of developing larger $V_{O C}$ despite a lack of electron blocking ability at the anode. In the case of the ITO, for instance, a reasonable open circuit voltage was still achieved despite a low shunt resistance. On the other hand, the FTO device showed an open circuit voltage of $0.55 \mathrm{~V}$ despite having a built in potential of only $0.3 \mathrm{~V}$, owing to the anode's ability to block electrons, as evidenced by the high device shunt resistance.

\subsection{Conclusion}

In conclusion, we have shown that FTO can be used as an indium-free TCO alternative to ITO for PCBM:P3HT devices, yielding power conversion efficiencies twice those of devices fabricated on ITO, without the need for a buffer layer. Using XPS core level and secondary spectra, it was shown that ozone treatment increased the work function of FTO and AZO without causing core level shifts. The increase in work function was consequently ascribed to the formation of a dipole layer due to oxygen termination of the surface. Finally, using device characteristics in conjunction with XPS 
surface measurements, the increase in efficiency observed for the FTO anode, and the open circuit voltage achieved by the various devices, was explained using a classical quasi-Fermi level framework. 


\section{Chapter 6. $\quad$ FTO for PbS Colloidal Quantum Dot Photovoltaics}

\subsection{Introduction}

Solution processable materials for photovoltaics offer a low-cost approach to producing large area solar installations. Polymer OPV systems have received much attention in recent years due to the fact that photoactive polymer layers can be spin coated, spray coated, or inkjet printed with relative ease. Small molecule and $\pi$ conjugated polymer materials used in organic photovoltaics typically absorb in the visible regime, leaving a large fraction of the infrared untapped. Conjugated polymers have generally shown spectral sensitivity only to $1000 \mathrm{~nm}$ [1]. Fully half of the sun's spectral power lies beyond $700 \mathrm{~nm}$ in the infrared [2]. There is therefore a need to extend the spectral reach of absorber materials to capture infrared light, which necessitates investigation of alternative material systems.

One promising approach to harvesting light in the NIR spectral range is the use of colloidal quantum dots (CQDs). Semiconducting CQDs, typically nanocrystals made from material combinations of II-VI semiconductors such as $\mathrm{PbS}, \mathrm{CdS}$, or $\mathrm{CdTe}$, offer the possibility of tuneable optical absorption extending into the near infrared. The bandgap of these materials can be increased or decreased through quantum size effect by controlling the average diameter of nanocrystals produced during synthesis [3]. Colloidal quantum dots can be synthesized in solution, employing controlled nucleation and growth with the help of ligands such as oleic acid [4]. Because of the necessity of employing organic ligands, photovoltaic CQD cells can be considered organic-inorganic hybrids. Often, 
nanocrystals are introduced into polymer matrices to sensitize PV devices to a certain spectral range [5]. Recently, CQD cells have achieved monochromatic power efficiencies of over 4\% [6]. The use of stacked CQD absorber layers, with each layer tuned to a different spectral absorbance, is a potential method for capturing more incoming sunlight. Fabrication of CQD cells in tandem with polymer or small molecule cells may offer a further route to capturing light across the sun's entire spectral range.

The most efficient CQD cells produced to date employ PbS quantum dots in simple planar structures as follows: ITO/PbS CQD film/Al [7]. In this structure, the $\mathrm{PbS}$ films forms a Schottky junction with the aluminum contact. The relative permittivities of PBS CQD films, measured to be $17 \pm 2$, are larger than for organic films [8]. Therefore, excitons generated in CQD films upon photon absorption tend to be much more weakly bound than for corresponding organic films. The carrier diffusion lengths for $\mathrm{PbS}$ films have been estimated as $100 \mathrm{~nm}$ [8]. Unfortunately, the optical absorption length for $\mathrm{PbS}$ CQD films is approximately $1000 \mathrm{~nm}$, mandating films of this same depth to achieve efficient light capture [8]. Carriers generated at a distance greater than one diffusion length $(100 \mathrm{~nm})$ from the $\mathrm{PbS} /$ Metal schottky junction, however, will tend to recombine before reaching the junction. A corresponding bottleneck exists for organic films, whose optical absorption length is typically $100 \mathrm{~nm}$ and whose exciton diffusion length is typically 5-20 nm. A central challenge for both types of cells will therefore be to raise diffusion lengths by raising carrier mobilities.

As with organic cells, all CQD cells require the use of a transparent conducting electrode. To our knowledge, ITO has been used almost exclusively for nanocrystal solar cell fabrication at the time of this writing. In one case, nanoporous ITO was used in an 
attempt to raise the active areas for PbS cells [9]. In the Schottky structure decribed above, the transparent anode is required to make an Ohmic contact with the CQD film for efficient hole extraction. In the following work, fluorine doped tin oxide is shown to be a suitable low-cost, indium-free alternative for use in PbS CQD cells.

\subsection{Experimental}

CQD devices were fabricated on FTO coated glass substrates purchased from Solaronix Inc. The FTO glass was $15 \Omega / \square$, with $400 \mathrm{~nm}$ films applied to $3 \mathrm{~mm}$ sheet glass. Reference devices were fabricated on ITO coated glass $(\sim 15 \Omega / \square)$ substrates. All substrates were cleaned in acetone, methanol and deionized water, followed by 15 minute UV-ozone treatment. PbS nanocrystals were synthesized using an organometallic route. The oleic acid capped nanocrystals were subsequently ligand-exchanged to n-butylamine in a nitrogen filled glovebox as described elsewhere [4]. Following the ligand exchange, CQD films were solution cast into films from $150 \mathrm{mg} / \mathrm{mL}$ octane solution by spin coating at $500 \mathrm{rpm}$ for 1 minute. Photovoltaic tests were performed using a Keithley $6430 \mathrm{sub}-$ femptoamp meter for IV scans, and a $975 \mathrm{~nm}$ laser diode providing illumination at 80 $\mathrm{mW} / \mathrm{cm}^{2}$.

Metal films were thermally evaporated in a BOC Edwards Auto 306 coating system with base pressure of $\sim 10^{-7}$ Torr. Film thicknesses were monitored using a calibrated quartz crystal monitor. Two photovoltaic device structures were fabricated simultaneously as follows: Device A: ITO/PbS/Al; Device B: FTO/PbS/Al. Device A was a baseline PV device made with ITO with which to compare device B made with FTO. Two hole-only devices were also fabricated as follows: Device $\mathbf{C}$ : ITO/PbS/Au; 
Device D: FTO/PbS/Au. Gold is a known Ohmic contact to PbS CQD films [10].

Therefore, the Ohmicity of the FTO vs ITO contacts to the PbS films could be observed in these devices. The various devices are depicted in figure 6.1 .
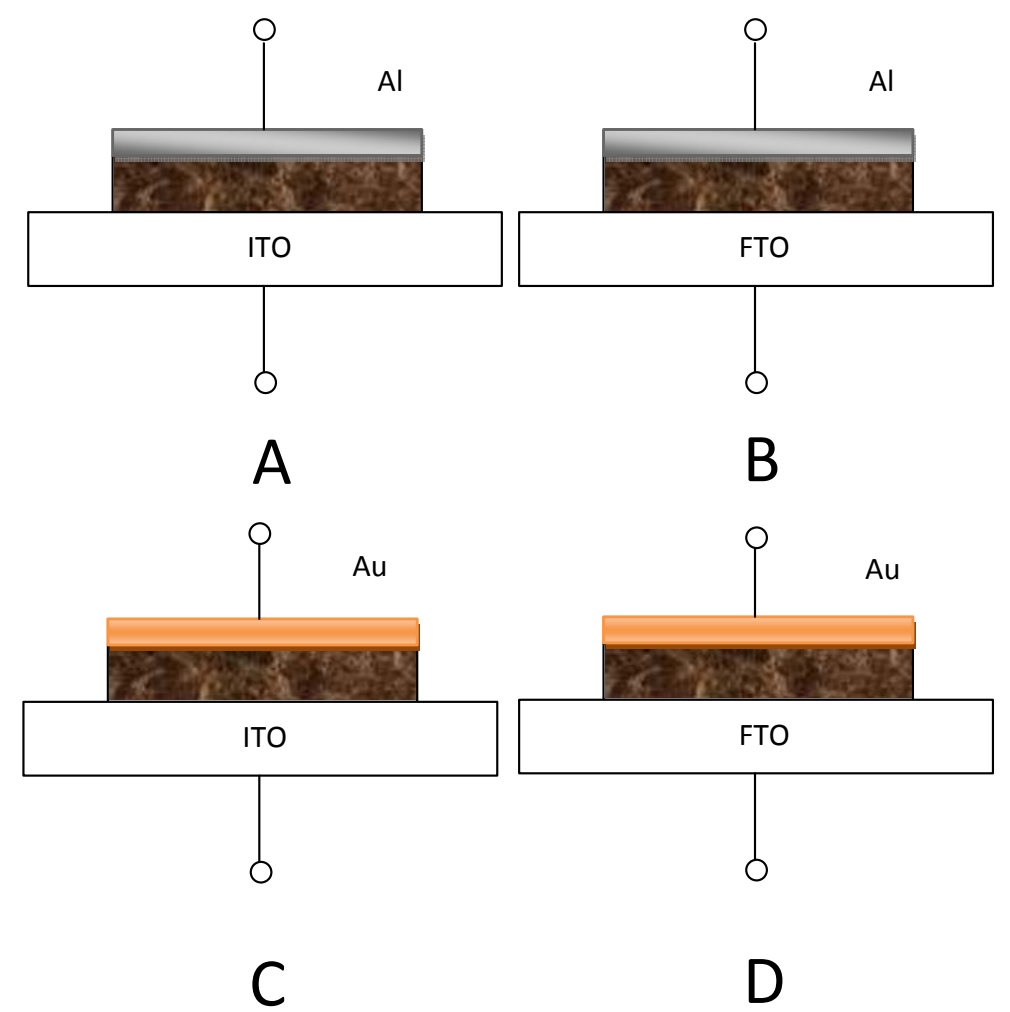

Figure 6.1. Photovoltaic cells ( $a$ and $b$ ) and hole only devices ( $c$ and $d$ ) employing FTO and ITO anode materials. Device structures are as follows: a) ITO/PbS/Al, b) FTO/PbS/Al, c) ITO/PbS/Au, d) FTO/PbS/Au.

FTO films are typically much rougher than ITO films of corresponding conductivity. Figure 6.2 a) shows an AFM image of the surface of cleaned, ozone treated FTO. The RMS roughness of the FTO film was found to be $13.1 \mathrm{~nm}$. For comparison, figure $6.2 \mathrm{~b}$ ) shows an AFM image of a polished, cleaned, and ozone treated ITO surface. The RMS roughness for the ITO surface is $3.9 \mathrm{~nm}$. For the specific application at hand, 
surface roughness is not problematic due to the fact that voids in the substrate surface are filled during spin coating.
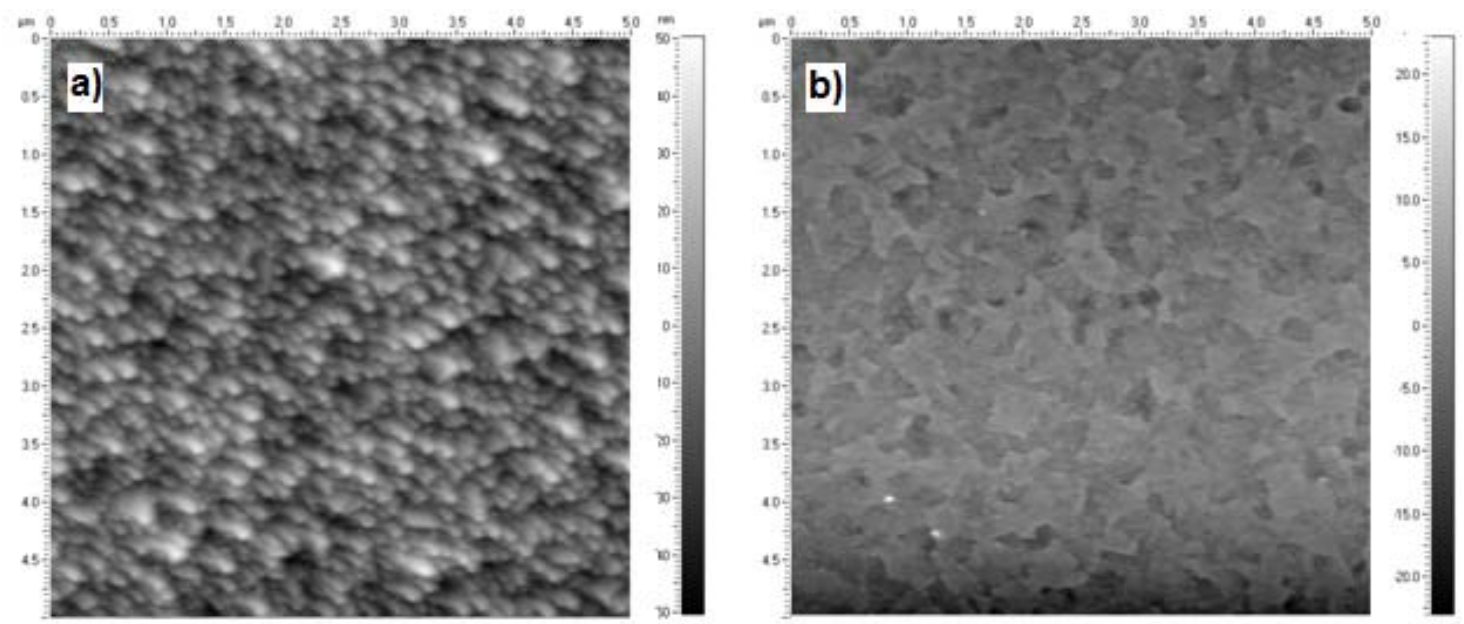

Figure 6.2. AFM image of a) FTO and b) ITO surfaces. The surface of unpolished FTO is much rougher than that of polished ITO.

\subsection{Results and Discussion}

Figure 6.3 shows the IV response of devices $\mathbf{A}$ and $\mathbf{B}$ under dark conditions and under $90 \mathrm{~mW} / \mathrm{cm}^{2}$ illumination. The open circuit voltages for both the ITO- and FTObased devices were the same at $0.34 \mathrm{~V}$. The short circuit current for the FTO device B was $6.84 \times 10^{-5} \mathrm{~A}$, and that of device $\mathbf{A}$ was $7.65 \times 10^{-5}$. Therefore the device performances were comparable within $10 \%$ power conversion efficiency and can be considered equivalent. Typical device-to-device variability in short circuit current for cells having nominally identical structure is larger than $10 \%$, owing to variations in the spin coating fabrication process. 


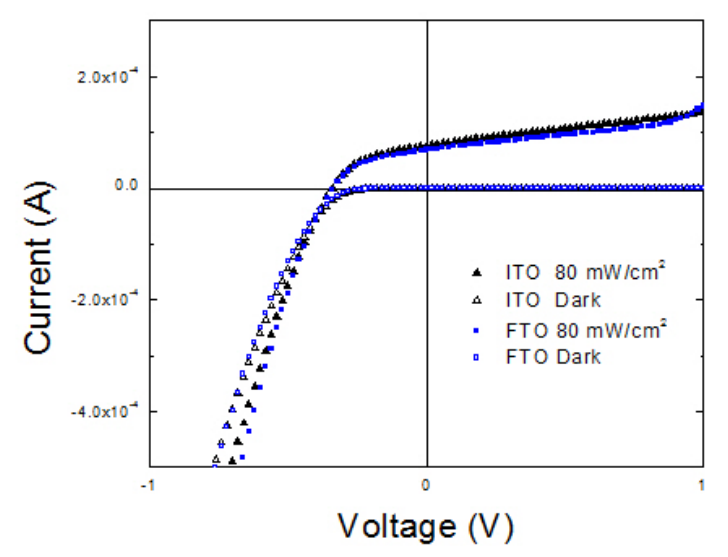

Figure 6.3. Current at $80 \mathrm{~mW} / \mathrm{cm}^{2}$ and dark illumination levels vs. voltage for CQD cells made using ozone treated ITO (device a) and FTO (device b).

Figure 6.4 depicts the IV relations for devices $\mathbf{C}$ and $\mathbf{D}$ under dark conditions and under $90 \mathrm{~mW} / \mathrm{cm}^{2}$ illumination. Both devices show photoconductive effect under illumination, but no photovoltaic effect. As mentioned above, Au films are known to form Ohmic contacts with $\mathrm{PbS}$ nanocrystal films. The linearity of the IV relation for device $\mathbf{C}$ therefore indicates that ITO is also Ohmic contact. The IV relation for device $\mathbf{D}$, on the other hand, shows a very slight sub-linearity under both dark and light conditions. The existence of a weak Schottky barrier is expected for the FTO case due to the fact that the work function of ozone treated FTO $(4.5 \mathrm{eV})$ is lower than that of ITO $(5.0 \mathrm{eV})$. Nevertheless, the relative weakness of the barrier is inconsequential to device performance, as demonstrated. 


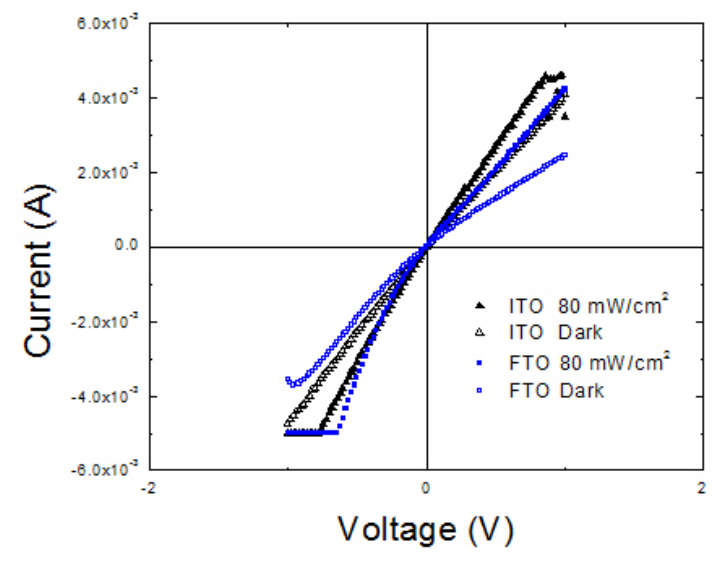

Figure 6.4. Current at $80 \mathrm{~mW} / \mathrm{cm}^{2}$ and dark illumination levels vs. voltage for CQD hole-only devices made using ozone treated ITO (device c) and FTO (device d).

\subsection{Conclusion}

In conclusion, FTO has been shown as a suitable ITO-free alternative transparent conductive anode material for PbS-based PV for the first time. Devices made with FTO and ITO exhibited the same short circuit voltage, despite the fact that the anode materials had work functions differing by $0.5 \mathrm{eV}$. Furthermore, CQD solar cells fabricated with FTO and ITO displayed power conversion efficiencies equivalent within 10\% EQE. Equivalent device performance is attributed to the ability of FTO to form a nearly Ohmic contact with $\mathrm{PbS}$ nanocrystals. 


\section{Chapter 7. Summary}

In the present work, suitable ITO anode replacement materials were demonstrated for small-molecule, polymer, and $\mathrm{PbS}$ colloidal quantum dot photovoltaics, as well as OLEDS. Table 7.1 summarizes the matrix of TCOs and devices tested in the present work. $\mathrm{Cu} / \mathrm{CuO}$ anodes were not applied to solar cells due to the fact that they are not transparent over the full visible spectrum; the peak in optical transmission was at $575 \mathrm{~nm}$ for these films, however, which was close to the $\mathrm{AlQ}_{3}$ emission peak at $525 \mathrm{~nm}$, allowing for efficient green OLED devices. FTO substrates were not applied to small molecule solar cells due to an RMS surface roughness (12 nm RMS) around half the thickness of typical organic absorption layers $(30 \mathrm{~nm})$; device shorting and low shunt resistance is expected for such devices.

Table 7.1. TCO Properties

\begin{tabular}{lllll}
\hline \hline Anode & FTO & AZO & ITO & $\mathrm{Cu} / \mathrm{CuO}$ \\
\hline \hline & & & & \\
Transmissivity $(\%)$ & $85 \%$ & $92 \%$ & $95 \%$ & $50 \% @ 575 \mathrm{~nm}$ \\
$\mathrm{R}_{\text {sheet }}(\Omega / \square)$ & 15 & $26-90$ & 15 & 25 \\
$\Phi(\mathrm{eV})$ & 4.5 & 4.7 & 5.1 & 5.3 \\
Relative cost & $\$ \$$ & $\$ \$$ & $\$ \$ \$ \$ \$$ & $\$$ \\
RMS Roughness (nm) & 13 & 6 & 3.9 & 3 \\
Process & Spray & DC Sputtering & RF Sputtering & Evaporation \\
& Pyroly & & & \\
& sis & & & \\
\hline Device efficiency & & & & \\
Small Molecule & - & 1.0 & 1.1 & \\
Bulk Heterojunction & 2.79 & 1.24 & 1.4 & \\
Colloidal Quantum Dot & & - & & \\
OLED & & & & \\
Comments & & & & \\
\hline \hline
\end{tabular}


Ultrathin films of copper, when treated with ozone gas to form $\mathrm{Cu} / \mathrm{CuO}$ bilayers, were found to work efficiently as ITO-free anodes for OLEDs; the high conductivity of the copper films allowed them to be made ultrathin, which ensured a degree of optical transparency close to the emission peak of $\mathrm{AlQ}_{3}$-based OLED devices. The high work function and smoothness of these films provided an excellent contact for hole injection at the OLED anode contact.

For the various solar cell applications, oxides with a high transparency over the entire visible range were required. FTO and AZO were selected as Indium-free replacements in these applications due to their clarity, high conductivity, chemical/mechanical stability, and non-toxicity. AZO as opposed to FTO was applied to small-molecule OPV devices due to its lower RMS roughness. AZO and FTO were both applied to polymer bulk-heterojunction cells due to less stringent requirements on roughness for this case. Small molecule cells made with ozone treated AZO were found to perform just as well as identical devices made with ITO. Ozone treatment prior to device fabrication was found to be a critical enabling element for the use of AZO in this application. Polymer solar cells fabricated on FTO were shown to produce devices that were twice as efficient as their ITO-based counterparts. Analysis of device characteristics as well as XPS analysis were used to explain the origin of the improvements in device performance. FTO was also shown as a suitable ITO-free alternative anode material for $\mathrm{PbS}$ colloidal quantum dot photovoltaic devices. Once again, the requirements for surface roughness were not stringent in this case due to the ability of the nanocrystals to intercalate into voids and crevices. Analysis of hole-only devices showed that FTO provided a quasi Ohmic contact to $\mathrm{PbS}$, showing only a slight rectification at the FTO 
$\mathrm{PbS}$ junction. When used as an anode material for PbS solar cells, FTO performed similarly to ITO, resulting in devices of equivalent open circuit voltage, and efficiencies equivalent within $10 \% \mathrm{EQE}$.

Although suitable ITO replacement materials were found for the various classes of devices studied above, these remains much room for improvement in terms of further lowering manufacturing costs. Of particular importance is the need to develop spincoatable, spray-coatable or printable transparent conductive materials that provide ITOequivalent performance when incorporated into organic devices. Investigation into such material systems is currently underway. In particular, films of graphene, carbon nanotubes and metallic nanowires have been applied to organic solar devices. Initial attempts show promise, but more work is required. Graphene sheets [1] and carbon nanotubes [2] do not match the conductivity of ITO. Metallic nanowires have shown to be competitive with ITO in terms of transparency, conductivity and organic solar cell performance [3]; however, the need for noble metals resulting in high costs, or the problem of oxidation of non-noble metals resulting in decreased device lifetime, may impede this method.

Recently, spin-coatable sol-gel synthesized antimony doped tin oxide (ATO) has been demonstrated as a TCO [4]. Initial results from Lu group show that ATO rivals FTO as an anode contact for PCBM:P3HT solar cells. More studies are required in order to optimize the films to achieve higher conductivity. The production of spin-coated conductive ATO or other oxide would break new ground if successful applied to polymer 
or small molecule solar cells. Such material systems would enable low-cost, flexible TCO films that are roll-to-roll processible, highly conductive, and robust. 


\section{Chapter 8. References}

Chapter 1 References

[1] R. G. Gordon, MRS Bull. 25, 52 (2000).

[2] J. C. C. Fan, and J. B. Goodenough, J. Appl. Phys. 48, 3524 (1977).

[3] T. Jansseune, Compd. Semicond. 11, 34. (2005).

[4] C.A. DiFrancesco, M.W. George, J.F. Carlin Jr., and A.C. Tolcin, "USGS Indium Report," Min. Yearbook (2007).

http://minerals.usgs.gov/minerals/pubs/commodity/indium/myb1-2007-indiu.xls

[5] A.C. Tolcin, "Indium," U.S.G.S. Min. Commod. Summ. (2008) http://minerals.usgs.gov/minerals/pubs/commodity/indium/mcs-2008-indiu.pdf

[6] A.C. Tolcin, "Indium," U.S.G.S. Min. Commod. Summ. (2009) http://minerals.usgs.gov/minerals/pubs/commodity/indium/mcs-2009-indiu.pdf

[7] J. M. Caruge, J. E. Halpert, V. Bulovic, and M. G. Bawendi, Nano Lett. 6, 2991 (2006).

[8] H. Kawazoe, M. Yasukawa, H. Hyodo, M. Kurita, H. Yanagi, and H. Hosono, Nature 389, 939-942 (1997).

[9] T. Mine, H. Yanagi, K. Nomura, T. Kamiya, M. Hirano, and H. Hosono, Thin Solid Films 516, 5790 (2008).

[10] S. Sheng, G. Fang, C. Li, Z. Chen, S. Ma, L. Fang, and X. Zhao, Semicond. Sci. Technol. 21, 586 (2006).

[11] K. Ueda, S. Inoue, S. Hirose, H. Kawazoe, and H. Hosono, Appl. Phys. Lett. 77, 2701 (2000).

[12] J.W. Ma, Z. Liang, C. Jin, X.Y. Jiang, Z.L. Zhanga, Sol. State Comm. 149, 214 (2009).

[13] I. M. Chan, T. Y. Hsu, and F. C. Hong, Appl. Phys. Lett. 81, 1899 (2002).

[14] M. D. Irwin, D. B. Buchholz, A. W. Hains, R. P. H. Chang, and T. J. Marks, PNAS 105, 2783 (2008).

[15] T. Minami, H. Nanto, and S. Takata, Appl. Phys. Lett. 41, 958 (1982).

[16] T. Minami, H. Nanto, and S. Takata, Jpn. J. Appl. Phys. 23280 (1984). 
Chapter 2 References

[1] J. Liu, T. Tanaka, K. Sivula, A. P. Alivisatos, and J. M. J. Fréchet, J. Am. Chem. Soc. 126, 6550 (2004).

[2] W. Shockley, and H. J. Queisser, J. Appl. Phys. 32, 510 (1961).

[3] M. A. Green, J. Zhao, A. Wang, and S. R. Wenham, IEEE Trans. on Electron. Dev., 46, 1940 (1999).

[4] I. Repins, M. A. Contreras, B. Egaas, C. DeHart, J. Scharf, C. L. Perkins, B. To, R. Noufi, Prog. Photovol.: Res. and Appl. 16, 235 (2008).

[5] Energy Information Administration, International Energy Annual (2006) http://www.eia.doe.gov/iea/ 2006

Last Updated: December 2008.

[6] Department of Energy, International Energy Outlook DOE/EIA-0484 (2009). http://www.eia.doe.gov/oiaf/ieo/

Released: May 27, 2009.

[7] N. Lewis, Caltech "The Future of Power and Energy in the World" (2004). http://online.kitp.ucsb.edu/online/colloq/lewis1/pdf/Lewis.pdf

[8] T. Surek, "Progress in U.S. Photovoltaics: Looking Back 30 Years and Looking Ahead 20" NREL.

http://www.nrel.gov/pv/thin_film/docs/surek_osaka_talk_final_vgs.pdf

[9] S. R. Forrest, MRS Bull. 30, 28 (2005).

[10] I.G. Hill, A. Kahn, Z.G. Soos, R.A. Pascal Jr., B Chem. Phys. Lett. 327, 181 (2000).

[11] P. Peumans, A.Yakimov, and S. R. Forrest, J. Appl. Phys. 93, 3693 (2003).

[12] C. Tang, Appl. Phys. Lett. 48, 183 (1986).

[13] P. Peumans, "The Science and Technology of Organic Solar Cells", SPIE lecture SC797.

[14] J. Xue, B. P. Rand, S. Uchida, and S. R. Forrest, Appl. Phys. Lett. 85, 5757 (2004).

[15] F. Yang, M. Shtein, and S. R. Forrest, Nat. Mater. 4, 39 (2005).

[16] B. P. Rand, P. Peumans, and Stephen R. Forrest, J. Appl. Phys. 96, 7519 (2004); 
[17] V. Bosle, J. T. Prater, F. Yang, D. Burk, S. R. Forrest, and J. Narayan, J. Appl. Phys. 102, 023501 (2007).

Chapter 3 References

[1] M. Chan and F. C. Hong, Thin Solid Films 450, 304 (2004)

[2] S. Y. Kim, J. M. Baik, H. K. Yu, and J. L. Lee, J. Appl. Phys. 98, 093707 (2005).

[3] J. Li, M. Yahiro, K. Ishida, H. Yamada, and K. Matsushige, Synth. Met. 151, 141 (2005).

[4] C. F. Qiu, Z. L. Xie, H. Y. Chen, M. Wong, and H. S. Kwok, J. Appl. Phys. 93, 3253 (2003).

[5] W. Hu, K. Manabe, T. Furukawa, and M. Matsumura, Appl. Phys. Lett. 80, 2640 (2002).

[6] S. Wang, T. Osasa, and M. Matsumura, Jap. J. Appl. Phys. 45, 8894 (2006).

[7] C. Di, G. Yu, Y. Liu Y. Guo, Y. Wang, W. Wu, and D. Zhu, Adv. Mater. 20, 1286 (2008).

[8] A. Mittiga, E. Salza, F. Sarto, M. Tucci, and R. Vasanthi, Appl. Phys. Lett. 88, $163502(2006)$.

[9] J. Ghijsen, L. H. Tjeng, J. van Elp, H. Eskes, J. Westerink, G. A. Sawatzky, and M. T. Czyzyk, Phys. Rev. B 38, 11322 (1988).

[10] J. C. Scott, G. G. Malliaras, Chem. Phys. Lett. 299, 115 (1999).

[11] J. C. Scott, J. Vac. Sci. Technol. A 21, 521 (2003).

[12] S. W. Tsang, Z. H. Lu, and Y. Tao, Appl. Phys. Lett. 90, 132115 (2007).

[13] R. Schlaf, C. D. Merritt, L. A. Crisafulli, and Z. H. Kafafi, J. Appl. Phys. 86, 5678 (1999).

[14] R. Schlaf, P. G. Schroeder, M. W. Nelson, and B. A. Parkinson, J. Appl. Phys. 86, 1499 (1999).

[15] S. Y. Kim, J. L. Lee, Appl. Phys. Lett. 89, 223515 (2006).

[16] F. P. Koffyberg and F. A. Benko, J. Appl. Phys. 53, 1173 (1982). 
[17] S. S. Jeong, A. Mittiga, E. Salza, A. Masci, and S. Passerini, Electrochim. Acta 53, $2226(2008)$.

Chapter 4 References

[1] C. Tang, Appl. Phys. Lett. 48, 183 (1986).

[2] J. Xue, B. P. Rand, S. Uchida, and S. R. Forrest, Appl. Phys. Lett. 85, 5757 (2004).

[3] J. Y. Kim, K. Lee, N. E. Coates, D. Moses, T. Nguyey, M. Dante, and A. J. Heeger, Science 317, 222 (2007).

[4] V. Bosle, J. T. Prater, F. Yang, D. Burk, S. R. Forrest, and J. Narayan, J. Appl. Phys. 102, 023501 (2007).

[5] A. V. Singh, N. Buthrath, A. Wakahara, A. Yoshida and R. M. Mehra, J. Appl. Phys. 90, 5661 (2001).

[6] J. C. Bernede, Y. Berredjem, L. Cattin, and M. Morsli, Appl. Phys. Lett. 92, 083304 (2008).

[7] K. Schulze, B. Maennig, Y. Tomita, C. May, J. Hüpkes, E. Brier, E. Reinold, P. Bäuerle, and K. Leo, Appl. Phys. Lett. 91, 073521 (2007).

[8] A. V. Singh and R. M. Mehra, A.Yoshida, A. Wakahara, J. Appl. Phys. 95, 3640 (2004).

[9] P. Peumans and S. R. Forrest, Appl. Phys. Lett. 79, 126 (2001).

[10] C. M. Ramsdale, J. A. Barker, A. C. Arias, J. D. MacKenzie, R. H. Friend, and N. C. Greenham, J. Appl. Phys. 92, 4266 (2002).

[11] B. Gregg, J. Phys. Chem. B 107, 4688 (2003).

[12] C. Uhrich, D. Wynands, S. Olthof, M. K. Riede, K. Leo, S. Sonntag, B. Maennig, and M. Pfeiffer, J. Appl. Phys. 104, 043107 (2008).

[13] B. Brousse, B. Ratier, and A. Moliton, Synth. Met. 147, 293 (2004).

Chapter 5 References

[1] C. Tang, Appl. Phys. Lett. 48, 183 (1986).

[2] J. Xue, B. P. Rand, S. Uchida, and S. R. Forrest, Appl. Phys. Lett. 85, 5757 (2004). 
[3] Potscavage, S. Yoo, B. Domercq, and B. Kippelen, Appl. Phys. Lett. 90, 253511 (2007).

[4] R. G. Gordon, MRS Bull. 25, 52 (2000).

[5] S. Shaheen, D. Ginley, and G. Jabbour, MRS Bull. 30, 11 (2005).

[6] G. Murdoch, S. Hinds, E. H. Sargent, S. W. Tsang, L. Mordoukhovski, and Z. H. Lu, Appl. Phys. Lett. 94, 213301 (2009).

[7] F. Yang and S. R. Forrest, Adv. Mater. 18, 2018 (2006).

[8] V. Bosle, J. T. Prater, F. Yang, D. Burk, S. R. Forrest, and J. Narayan, J. Appl. Phys. 102, 023501 (2007).

[9] J. C. Bernede, Y. Berredjem, L. Cattin, and M. Morsli, Appl. Phys. Lett. 92, 083304 (2008).

[10] K. Schulze, B. Maennig, Y. Tomita, C. May, J. Hüpkes, E. Brier, E. Reinold, P. Bäuerle, and K. Leo, Appl. Phys. Lett. 91, 073521 (2007).

[11] M. Grätzel, MRS Bull. 30, 23 (2005).

[12] A. V. Singh, N. Buthrath, A. Wakahara, A. Yoshida and R. M. Mehra, J. Appl. Phys. 90, 5661 (2001).

[13] H. Y. Yu, X. D. Feng, D. Grozea, Z. H. Lu, R. N. S. Sodhi, A-M. Hor and H. Aziz, Appl. Phys. Lett. 78, 2595 (2001).

[14] R. Schlaf, C. D. Merritt, L. A. Crisafulli, and Z. H. Kafafi, J. Appl. Phys. 86, 5678 (1999).

[15] R. Schlaf, P. G. Schroeder, M. W. Nelson, and B. A. Parkinson, J. Appl. Phys. 86, 1499 (1999).

[16] C. Uhrich, D. Wynands, S. Olthof, M. K. Riede, K. Leo, S. Sonntag, B. Maennig, and M. Pfeiffer, J. Appl. Phys. 104, 043107 (2008).

Chapter 6 References

[1] M. M. Wienk, M. G. R. Turbiez, M. P. Struijk, M. Fonrodona, and R. A. J. Janssen, Appl. Phys. Lett. 88, 153511 (2006).

[2] E. H. Sargent, IEEE Journal of Selected Topics in Quantum Electronics 14, 1223 (2008). 
[3] L. Bakueva, S. Musikhin, M. A. Hines, T.-W. F. Chang, M. Tzolov, G. D. Scholes, and E. H. Sargent, Applied Physics Letters 82, 2895 (2003).

[4] G. Konstantatos, I. Howard, A. Fischer, S. Hoogland, J. Clifford, E. Klem, L. Levina, and E. H. Sargent, Nature 442, 180 (2006).

[5] S. Guenes, K. P. Fritz, H. Neugebauer, N. S. Sariciftci, S. Kumar, and G. D. Scholes, Sol. Energ. Mater. Sol. Cells 91, 420 (2007).

[6] K. W. Johnston, A. G. Pattantyus-Abraham, J. P. Clifford, S. H. Myrskog, S. Hoogland, H. Shukla, E. J. D. Klem, L. Levina, and E. H. Sargent, Appl. Phys. Lett. 92, 122111 (2008).

[7] K. W. Johnston, A. G. Pattantyus-Abraham, J. P. Clifford, S. H. Myrskog, D. D. MacNeil, L. Levina, and E. H. Sargent, Appl. Phys. Lett 92, 151115 (2008).

[8] E. H. Sargent, Nature Photonics 3, 325 (2009).

[9] E. J. D. Klem, D. D. MacNeil, P. W. Cyr, L. Levina, and E. H. Sargent, Appl. Phys. Lett. 90, 183113 (2007).

[10] J. P. Clifford, G. Konstantatos, K. W. Johnston, S. Hoogland, L. Levina, and E. H. Sargent, Nature Nanotechnology 4, 40 (2008).

Chapter 7 References

[1] J Wu, H. A. Becerril, Z. Bao, Z. Liu, Y. Chen, and P Peumans, Appl. Phys. Lett. 92, 263302 (2008).

[2] M. W. Rowell, M. A. Topinka, M. D. McGehee, H.-J. Prall, G. Dennler, N. S. Sariciftci, L. Hu, and G. Gruner, Appl. Phys. Lett. 88, 233506 (2006).

[3] J. -Y. Lee, S. T. Connor, Y. Cui, and P. Peumans, Nano Lett. 8, 689 (2008).

[4] C. Goebbert, H. Bisht, N. Al-Dahoudi, R. Nonninger, M.A. Aegerter, H. Schmidt, Jour. of Sol-Gel Sci. and Tech. 19, 201 (2000). 